OPEN ACCESS

Edited by:

Zhenyu Jia,

University of California, Riverside

United States

Reviewed by:

Kwok-Ming Yao,

The University of Hong Kong,

Hong Kong

Qingbin Cui,

University of Toledo Medical Center.

United States

*Correspondence:

Zhixia Zhou

zhou_zhixia@qdu.edu.cn

Peifeng $L i$

peifeng@ioz.ac.cn

Specialty section:

This article was submitted to

Molecular and Cellular Oncology,

a section of the journal

Frontiers in Oncology

Received: 29 June 2020

Accepted: 28 August 2020

Published: 25 September 2020

Citation:

Zhou Z, Gong Q, Lin Z, Wang Y, Li M, Wang L, Ding $H$ and Li P (2020)

Emerging Roles of SRSF3 as a

Therapeutic Target for Cancer.

Front. Oncol. 10:577636.

doi: 10.3389/fonc.2020.577636

\section{Emerging Roles of SRSF3 as a Therapeutic Target for Cancer}

\author{
Zhixia Zhou ${ }^{1 *}$, Qi Gong ${ }^{2}$, Zhijuan Lin ${ }^{3}$, Yin Wang ${ }^{1}$, Mengkun Li ${ }^{1}$, Lu Wang ${ }^{1}$, Hongfei Ding ${ }^{1}$ \\ and Peifeng $\mathrm{Li}^{1 *}$ \\ ${ }^{1}$ Institute for Translational Medicine, The Affiliated Hospital of Qingdao University, College of Medicine, Qingdao University, \\ Qingdao, China, ${ }^{2}$ Departments of Pediatrics, Second Clinical Medical College of Qingdao University, Qingdao, China, ${ }^{3}$ Key \\ Laboratory for Immunology in Universities of Shandong Province, School of Clinical Medicine, Weifang Medical University, \\ Weifang, China
}

Ser/Arg-rich (SR) proteins are RNA-binding proteins known as constitutive and alternative splicing (AS) regulators that regulate multiple aspects of the gene expression program. Ser/Arg-rich splicing factor 3 (SRSF3) is the smallest member of the SR protein family, and its level is controlled by multiple factors and involves complex mechanisms in eukaryote cells, whereas the aberrant expression of SRSF3 is associated with many human diseases, including cancer. Here, we review state-of-the-art research on SRSF3 in terms of its function, expression, and misregulation in human cancers. We emphasize the negative consequences of the overexpression of the SRSF3 oncogene in cancers, the pathways underlying SRSF3-mediated transformation, and implications of potential anticancer drugs by downregulation of SRSF3 expression for cancer therapy. Cumulative research on SRSF3 provides critical insight into its essential part in maintaining cellular processes, offering potential new targets for anti-cancer therapy.

Keywords: SRSF3, oncogene, RNA splicing, cancer, alternative splicing

\section{BACKGROUND}

Ribonucleic acid (RNA) splicing is a fundamental process of gene expression, during which non-coding sequences (introns) are removed and coding sequences (exons) are ligated together from a precursor messenger RNA (pre-mRNA) to form a mature messenger RNA (mRNA) (1). In higher eukaryotes, most genes undergo alternative splicing from a single pre-mRNA transcript via splice site selection, generating multiple mature mRNAs that have different functions and contribute to biologic complexity (Figure 1). Both constitutive and alternative splicing processes are catalyzed by dynamic and complex macromolecular major (U2-dependent) or minor (U12-dependent) spliceosomes (2). Each spliceosome contains five small nuclear ribonucleoprotein (snRNPs) particles: U1, U2, U4, U5, and U6 snRNAs for former and U11, U12, U4atac, U5, and U6atac snRNAs for the latter (3). Spliceosome recognizes the consensus sequence elements at the 5'ss, 3'ss, and branch point (BP) sites, which is a crucial step in the splicing pathway (3). The selection of splice sites for recognition is modulated by an array of RNA regulatory sequence elements, including exonic and intronic splicing enhancers and silencers. These splicing regulatory elements (SREs) are recognized by numerous accessory splicing factors, including the heterogeneous nuclear ribonucleoproteins (hnRNPs) and Ser/Arg-rich (SR) proteins (3). SR proteins and hnRNPs promote and suppress splicing, respectively, in a sequence-depending manner and in diverse ways, including facilitating the recruitment of U1 or U2 snRNP, occluding a splice site, and "looping out" an exon (4). In addition to their role as splicing regulators, these 


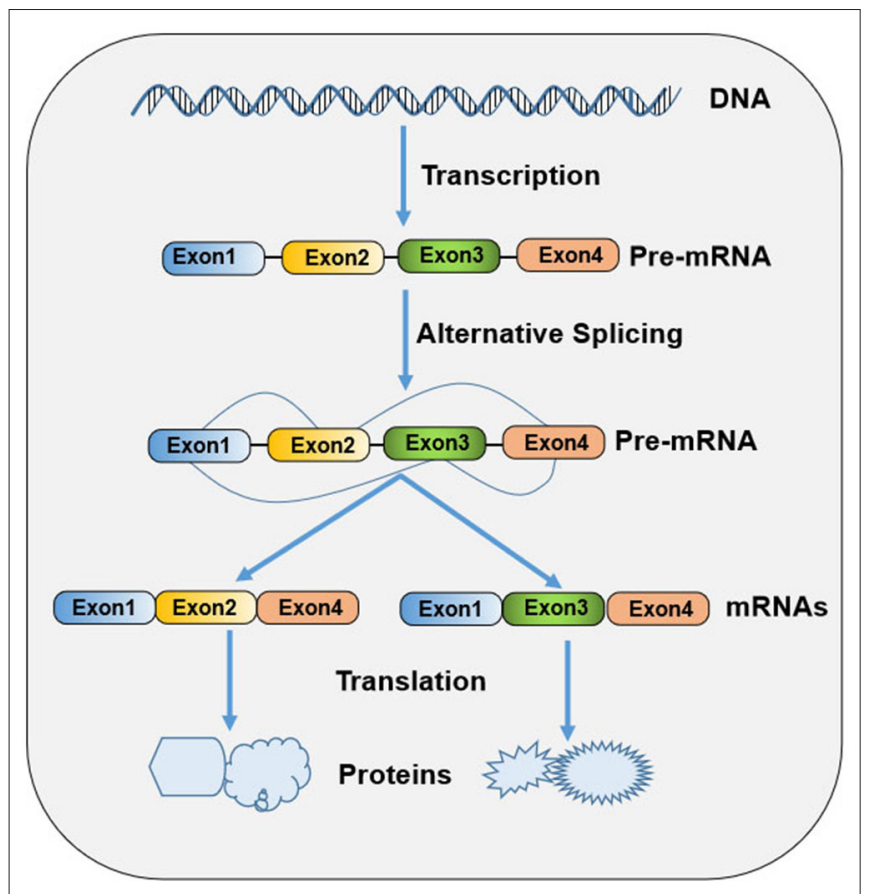

FIGURE 1 | Schematic diagram of gene expression in prokaryote cells.

proteins also participate in other diverse RNA metabolic processes and cellular processes, such as Pol II transcription, mRNA export and translation, genomic stability maintenance, cell viability, and cell-cycle progression (5).

Abbreviations: ABC, ATP-binding cassette; BP, Branch point; AS, Alternative splicing; CLK, CDC2-like kinase; CRC, Colorectal cancer; CTD, C-terminal domain; DARPP-32, Dopamine and cyclic adenosine monophosphate-regulated phosphoprotein, Mr 32000; DNA, Deoxyribonucleic acid; ESE, Exonic splicing enhancer; FL, Follicular lymphoma; FoxM1, Forkhead box transcription factor M1; GBM, Glioblastoma; GSC, Glioma stem-like cells; GV, Germinal vesicle; GVBD, Germinal vesicle breakdown; HBx, Hepatitis B virus-encoded $\mathrm{X}$ protein; HCC, Hepatocellular carcinoma; HIPK2 FL, Full-length HIPK2; HIPK2, Homeodomain-interacting protein kinase2; hnRNPs, Heterogeneous nuclear ribonucleoproteins; HPV, Human papillomavirus; HRR, Homologous recombination repair; IGC, Interchromatin granule cluster; IR, Intron retention; IRES, Internal ribosome entry site; JNK, c-Jun N-terminal protein kinase; MAP4K4, Mitogen-activated protein 4 kinase 4; MCC, Mutated in colorectal cancer; miRNA, MicroRNA; mRNA, Messenger RNA; MRP1, Multidrug resistance protein 1; NAFLD, Nonalcoholic fatty liver disease; NASH, Non-alcoholic steatohepatitis; NRS, Negative regulator of splicing; NXF1, Nuclear export factor 1; NXF1-NXT1, NXF1-nuclear transport factor 2-related export protein 1; PBs, P-bodys; PDCD4, Programmed cell death; PKM, Pyruvate kinase M; PKM2, Pyruvate kinase muscle 2; PLC, Phospholipase C; pre-mRNA, Precursor messenger RNA; pri-miRNAs, Primary microRNA transcripts; PTB, Polypyrimidine tractbinding protein; PTC, Premature termination codon; RBM4, RNA-binding motif protein 4; RBPs, RNA-binding proteins; RNA, Ribonucleic acid; ROS, Reactive oxygen species; RI, Retained intron; RRM, RNA-recognition motif; RS, Arginine (R) and Serine (S); RSV, Rous sarcoma virus; SCC, Sister chromatid cohesion; SELEX, Systematic evolution of ligands by exponential enrichment; snRNPs, Small nuclear ribonucleoproteins; SR, Ser/Arg-rich; SRE, Splicing regulatory element; SRPK, SR protein kinase; SRSF, Ser/Arg-rich Splicing Factor; TL, Terminal loop; TNBC, Triple-negative breast cancer; TNM, Tumor node metastasis; UTR, Untranslated region; YTHDC1, YTH domain containing 1.
An increasing body of evidence supports that the aberrant splicing of pre-mRNA results in the production of aberrant proteins that contribute to the misregulation of cellular growth, differentiation, and tissue development, eventually leading to the susceptibility to diseases, including cancer (6). Recent studies have found that alterations and mutations in the genes encoding core spliceosomal proteins and related RNA-splicing factors provide major mechanisms for cancer-associated splicing and transformation, implicating tumor establishment, progression, and resistance to therapy $(4,6)$. Many splicing factors, including SR and hnRNP families, have been certified to act as both oncoproteins (or proto-oncoproteins) and tumor suppressors. Therefore, we focus on Ser/Arg-rich splicing factor 3 (SRSF3), also called SRp20, which is a member of the highly conserved SR protein family. SRSF3 plays a critical role in the regulation of RNA splicing and many other cellular functions. Aberrant SRSF3 function can be identified in several human diseases, including Alzheimer's disease (7), systolic heart failure (8), ocular hypertension (9), virus infection (10-12), and tumor (13). In this review, we summarize current research on the function and expression regulation of SRSF3 and the misregulation and biological implications of SRSF3 in cancer, as well as its therapeutic potential.

\section{SRSF3 FUNCTIONS}

SR protein family are identified by possessing one or two $\mathrm{N}$ terminal RNA-recognition motif (RRM) domains and a Cterminal domain enriched with the Arginine (R) and Serine (S) amino acid sequences (RS domain). In general terms, RRM domains recognize RNA, whereas RS domains take part in diverse protein-protein and protein-RNA interactions $(14,15)$. Thus, far, 12 members of the SR protein family have been identified in humans, encoded by 12 genes and designated SRSF1-12. All members of the SR protein family are mainly nuclear and localize to interchromatin granule clusters (IGCs) or nuclear speckles, but some members including SRSF3 can shuttle between the nucleus and the cytoplasm (15-17). SR proteins have been shown to regulate constitutive and alternative splicing as well as multiple other steps of RNA biological metabolism, suggesting that they are multifunctional proteins taking part in transcriptional, co-transcriptional, and post-transcriptional regulation pathways $(18,19)$. Given the important roles that SR proteins act on these processes, aberrant expression and/or activation and somatic mutation in SR proteins would lead to developmental impairments and disease pathophysiology $(4,20)$.

SRSF3 composes 164 amino acids with $19 \mathrm{kDa}$ molecular weight makes it to be the smallest member of the SR protein family (13). Although initially identified as a splicing regulator, SRSF3 has been identified as a polyfunctional protein involved in multiple physiological and pathological processes, as shown in Figure 2.

\section{Regulation of Splicing}

SRSF3 regulates the global change in gene expression program to maintain cell homeostasis by constitutive splicing and alternative splicing (21). Alternative splicing is an essential process for 


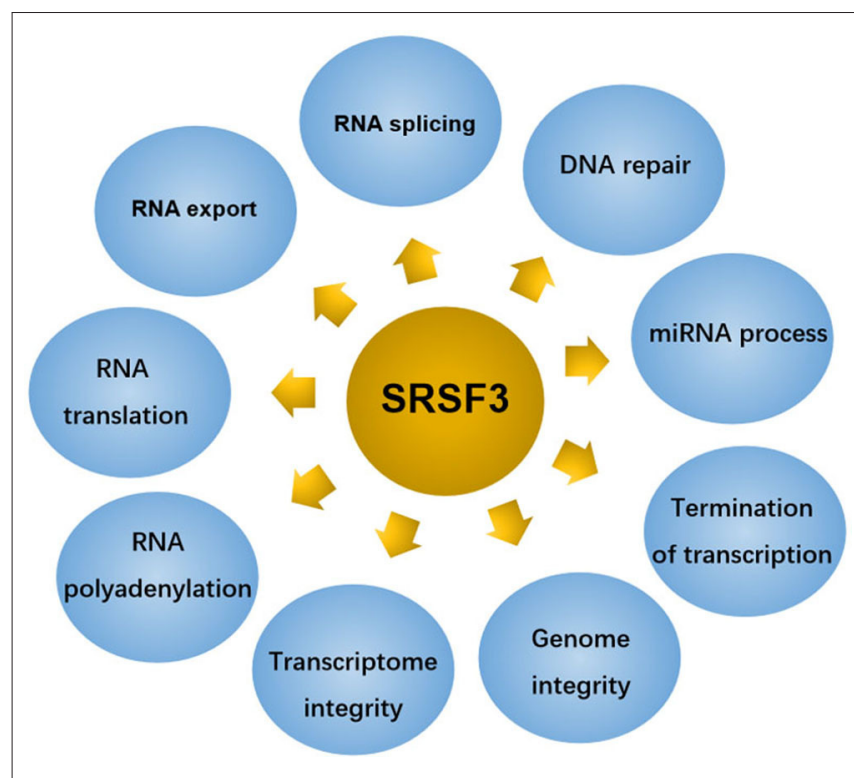

FIGURE 2 | SRSF3 regulates several cellular functions in eukaryote cells.

regulating most protein-coding genes by producing multiform messenger RNA transcripts to yield proteomic diversity in eukaryotic cells. Several distinct patterns of SRSF3-induced alternative splicing exist, including mutually exclusive exons (22), alternative terminal exons (23), alternative cassette exons (where one or more exons is either skipped or included) (2426), alternative unique exon (27), skipping of 5'-nucleotides from exon (28), intron retention (IR) $(29,30)$, and early termination codon (30). In addition, SRSF3 can act as activators or repressors in the alternative splicing of other RNA-binding proteins (RBPs), such as SRSF1 (31), SRSF5 (32), C-terminal domain (CTD) of RNA polymerase II (pol II) (25), polypyrimidine tract-binding protein (PTBP) 1 and heterogeneous nuclear ribonucleoprotein (hnRNPs) A1 (33). Similar to other SR members, SRSF3-related aberrant splicing is often associated with the non-sense-mediated mRNA decay pathway, resulting in inducing aberrant protein isoforms that are often linked to numerous human diseases, including cancers.

\section{Regulation of RNA Export}

The ability of SRSF3 to shuttle between the nucleus and the cytoplasm allows it to be a major contributor to the regulation of mRNA export. Similar to other SRSFs, the nuclear to cytoplasmic translocation of SRSF3 relates to the export receptor, nuclear export factor 1 (NXF1) via Arginine-rich peptide adjacent to RRM (34). Among those SRSFs, SRSF3 presents the most effective adaptor for the NXF1 adaptor (35), suggesting that SRSF3 can act as a sturdy ship in the TAP-dependent mRNA export from nucleus to cytoplasm. SRSF3 represses nuclear export of programmed cell death (PDCD4), isoform 2 mRNA. Consequently, at SRSF3 knockdown, PDCD4 AS-2 mRNA level, but not $A S-1$, was found to increase in the cytoplasm (36). In addition, SRSF3 can interact with NXF1-nuclear transport factor 2-related export protein 1 (NXF1-NXT1), resulting in the export of “intronless" mRNAs (37).

\section{Regulation of RNA Translation}

SRSF3 can mediate post-transcriptional regulation of mRNA. It presents an internal ribosome entry site (IRES) and mediates the translation initiation of viral RNA in company with PCBP2, an IRES-binding protein (38). Moreover, it was reported that SRSF3 is not only participating in pre-mRNA alternative splicing but also in the regulation of the translation of PDCD4 mRNA. Of the two alternatively spliced transcripts of PDCD4, only isoform 1 (the major isoform) was found to be affected at the translational level by SRSF3. Further study found that SRSF3 exerted its effect on PDCD4 mRNA translation through a strong interaction with the 5'-untranslated region (5'-UTR) and recruitment to P-bodys (PBs). When SRSF3 was silencing, $\mathrm{PBs}$ disappeared and the translation inhibition of PDCD4 mRNA was relieved. These data investigate that SRSF3 recruits PDCD4 mRNA to PBs for the expression of PDCD4 (36, 39). In addition, a reproducible hypoxia-induced increase in SRSF3 protein was associated with the hypoxic stress-induced retained intron (RI) in translation initiation of EIF2B5 (29). RI in EIF2B5 creates a premature termination codon (PTC), leading to a $65 \mathrm{kDa}$ truncated protein isoform that opposes full-length $\mathrm{eIF} 2 \mathrm{~B} \varepsilon$ to inhibit global translation. Upon SRSF3 knockdown, the expression of the $65 \mathrm{kDa}$ isoform of eIF2B $\varepsilon$ disappearances in normoxia or hypoxia conditions. Then the biding between SRSF3 protein and EIF2B5 mRNA was proved to increased (29). These results indicate SRSF3 as a regulator mediating RI in EIF2B5, consequently taking part in translational control under hypoxia. Moreover, SRSF3 was identified as a translation regulator of innate immune genes, which may be because there are several putative binding sites for SRSF3 in $3^{\prime}$ UTRs of some innate immune gene (40). As expected, SRSF3 silencing led to the increase in the protein synthesis of immune mediators, containing SAA3, CCL5, and CCL3, suggesting that SRSF3-mediated translational regulation is involved in innate immunity (40).

\section{Regulation of RNA Polyadenylation}

Polyadenylation is a processing step for generating mature mRNA in eukaryotes (41). In the model for the negative regulator of splicing (NRS)-stimulated Rous sarcoma virus (RSV) polyadenylation, it was shown that SR proteins, including ASF/SF2, 9G8, and SRSF3, binding to NRS- or systematic evolution of ligands by exponential enrichment (SELEX)binding sites was sufficient to stimulate polyadenylation in vitro. However, just SR protein-binding sites promoted polyadenylation independent of the NRS complex in vivo when moved nearer to the viral poly(A) site. Data manifest that SR proteins play a promoting role in RSV polyadenylation, but only when they are close to the RNA $3^{\prime}$ end by binding to the NRS (42). In addition, SRSF3 was reported to affect the recognition of an alternative $3^{\prime}$-terminal exon by effecting the efficiency with which a polyadenylation factor is bound to an alternative polyadenylation site (43). These results suggest that SR proteins 
not only regulators the polyadenylation of cellular mRNAs but also controls alternative polyadenylation.

\section{Regulation of Transcriptome Integrity}

SRSF3 is also reported to contribute to the establishment and modulation of the maternal transcriptome (19). SRSF3 was proved to highly express in germinal vesicle (GV) and MII oocytes (at metaphase of meiosis II), indicating SRSF3 acting as a critical maternally inherited factor. SRSF3 knockdown in grown germinal vesicle oocytes compromises the capacity of germinal vesicle breakdown (GVBD). Further, the GVBD defect in mutant oocytes was proved to be due to both aberrant alternative splicing (including $\mathrm{Brd} 8$ and $\mathrm{Pdlim} 7$ ) and depression of B2 SINE transposable elements. These observations suggest that the control of the transcriptional identity of the maternal transcriptome by SRSF3 is essential to the development of fertilized competent oocytes (19).

\section{Regulation of Genome Integrity}

DNA lesions are usually caused by chemical compounds with (pro-)genotoxic activity and dysregulations of basic processes, including transcription, DNA replication, and mitosis (44). Mitotic distortions and transcription-associated RNA-DNA hybrids (R-loops) formations induced by impaired expression of RNA-binding proteins are strongly associated with DNA injury (45). SLU7 as a key mediator of genome stability was reported to be required for the mitotic progression of transformed cells, suitable spindle assembly, sister chromatid cohesion (SCC), and sororin splicing regulation, as well as for the protecting cells from R-loop formation and DNA damage (45). SLU7 knockdown leads to the formation of R-loops, DNA damage, cell-cycle arrest, and SCC loss. Further study found that SLU7 regulates the splicing of SRSF1 and SRSF3 and inhibites the protein expression of truncated SRSF3 (SRSF3-TR) (45). These results demonstrate that SRSF3-TR proteins, as a target of SLU7, may play a important role in DNA damage and genome instability.

\section{Regulation of Transcription Termination}

Termination of RNA polymerase II (Pol II)-mediated transcription acts a significant role in the regulation of gene expression (46). The transcription termination of RNA polymerase II (Pol II) contains two linked steps: mRNA $3^{\prime}$-end formation and Pol II release from DNA. The intact $3^{\prime}$-processing signal and some $3^{\prime}$-end processing factors are also required for Pol II transcription termination $(47,48)$. In the model of a C. elegans operon intended to select factors taking part in the transcription termination, the lin- 15 operon involves two genes: lin-15B and lin-l5A (49). Two deletion alleles of rsp-6, which encodes SRSF3, were found to strongly suppress the synthetic Multivulva phenotype of lin-15AB (n765) at levels similar to RNAi. In lin-15AB, RNA levels decrease markely at the site of the insertion, whereas they restore at the site of the insertion in the rsp-6 mutant strain. Further, SRSF3 was found to increase the RNA downstream of the cleavage site without influencing cleavage (49). These data indicate that SRSF3 acts a role in termination of transcription and not in cleavage, maybe by interacting with the RNA downstream of the cleavage site.

\section{Regulation of miRNA Process}

SRSF3 was also demonstrated to facilitate primary microRNA transcripts (pri-miRNAs) recognition and processing. PrimiRNAs own at least one RNA motif in the major and conserved motif family: UG, UGU, and CNNC (50). The UG and UGU motifs of pri-miRNAs cooperate with the microprocessor complex (including RNase III DROSHA and DGCR8 dimer) to cleave pri-miRNAs to initiate microRNA (miRNA) maturation, whereas CNNC connects with SRSF3 to induce the microprocessor to process pri-miRNAs. That is, SRSF3 supplies DROSHA to the foundational junction in a CNNC-dependent manner, then improving microprocessor activity (50). For example, a genetic variant (G27-to-A variant) in the terminal loop ( $T L)$ of pri-mir-30c-1 leads to the reorganization of the RNA secondary structure, thereby promotes the interaction of pri-mir-30c-1 with SRSF3. And the interaction between them occurs at the CNNC motif located 17 nucleotides away from the Drosha cleavage site at the basal region of the G/A variant. This interaction, also increases the microprocessor-mediated processing of primir-30c-1, causing the upregulation of miR-30c level (51). In addition, expressions of mature miR-1908-5p (52) and miR-3131 (53) were also mediated by SRSF3. NF-кB was also shown to be involved in SRSF3-regulated miR-1908 expression (51).

\section{Regulation of DNA Repair}

Recently, SRSF3 was identified as a regulator of the homologous recombination-mediated DNA repair (HRR) process, which may regulate the HRR-related gene expression indirectly by an epigenetic pathway (54). SRSF3 knockdown impaired HRR activity and improved the level of $\gamma$-H2AX which ating as a biomarker for double-strand DNA breaks. It also downregulated the genes involved in HRR, including BRCA1, $B R I P 1$, and RAD51, changed the KMT2C (a H3K4-specific histone methyltransferase) splicing pattern, and decreased the mono- and trimethylated H3K4 level (54).

\section{SRSF3 EXPRESSION REGULATION}

Given the above, SRSF3 is an essential gene for embryogenesis. SRSF3 exists in oocytes and the early phase of embryonic development $(19,55)$, and SRSF3 missing leads to the arrest at one/two-cell developmental stage (19). In addition, it was found that the SRSF3-zygotic knockout embryos, using CreloxP-mediated recombination in mice to stimulate the expression of SRSF3 gene, died at the morula stage, failing to form blastocysts (55). Contrarily, the overexpression of SRSF3 in rodent fibroblasts leads to tumorigenesis with immortal cell growth and transformation (11). Thus, the SRSF3 level in cells is controlled by multiple factors and involves complex mechanisms, as shown in Figure 3.

\section{Autoregulation}

Autoregulation is a common mechanism for maintaining relatively stable expression of splicing factors (56). SRSF3 is the first SR protein identified as a auto-regulator for itself alternative splicing and be regulated by other members of the 


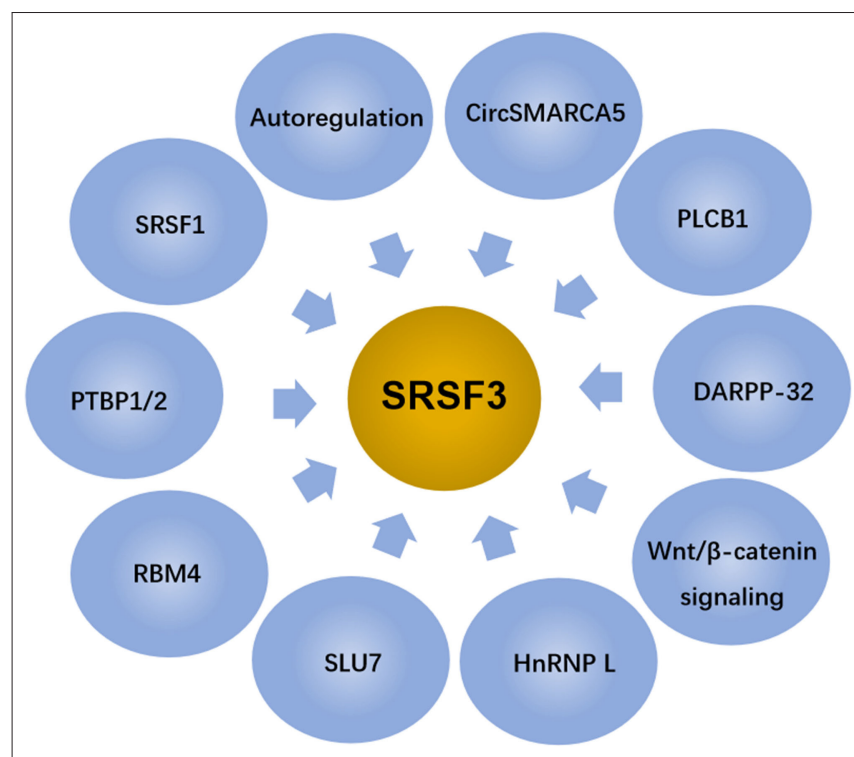

FIGURE 3 | SRSF3 expression is regulated by several factors and signaling pathways.

SR protein family (57). Genomic SRSF3 constructs are able to express two different forms of SRSF3 because of the alternative splicing of exon 4 (also referred to as intron 3 owning an inframe stop codon), generating a full-length isoform that lacks exon 4 (Iso1) and an alternative isoform that includes exon 4 (Iso2) $(57,58)$. The overexpression of SRSF3 reduces the level of exon 4-skipped SRSF3 transcripts and activates the outcome of transcripts containing exon 4 (SRSF3-ISO2), resulting in a truncated protein lacking the C-terminal RS domain SRSF3-TR later, which has been identified as an autoregulatory mechanism for avoiding SRSF3 accumulation $(44,57)$.

\section{Regulation by Other Splicing Factors}

Besides autoregulation, SRSF3 interacts with other RNA binding proteins, including other SR splicing factors. SRSF1 (also called ASF/SF2), another member of the SR family, can lead to the disappearance of the exon 4 -included isoform without affecting the amount of the skipped isoform. The outcome of the included isoform is restrained by SRSF1 even in the presence of the transfection of wild-type genomic SRSF3, suggesting that SRSF1 is dominant over SRSF3 in this system. These results indicate that SRSF1 and SRSF3 have adverse effects on SRSF3 exon 4 splicing with SRSF3 playing as an activator and SRSF1 as a suppresser (57). In addition to SRSF1, other splicing factors including PTBP1 and PTBP2, can also antagonize the autoregulation of SRSF3 splicing. PTBP1 overexpression and the presence of neuron-enriched homolog of PTBP1 and PTBP2 can shift the transcript expressions from coding SRSF3 to $S R S F 3^{+}$exon $4^{\prime}$ (59). Further study found that PTBP1 and PTBP2 can inhibit the inclusion of an exonic splicing suppressor (an ESS motif with pyrimidine-rich) by binding to it, which leads to the overexpression of full-length SRSF3 (56). In addition, RNAbinding motif protein 4 (RBM4) (an antagonizer of PTBPs), was studied to determine whether it has a antagonistic effect on SRSF3 splicing regulation (59). Results show that RBM4 overexpression robustly shifts the transcript expressions from coding SRSF3 to SRSF3 $3^{+ \text {exon }} 4^{\prime}$, whereas RBM4 excision inversely resulted in the increasing of the coding SRSF3 transcript. The mutations of RNA recognition motif or substitution of the serine-toaspartate (S309D) impedes the impact of RBM4 on productions of SRSF3 ${ }^{+ \text {exon } 4^{\prime}}$ transcripts, which suggests that RBM4 interferes with SRSF3 splicing at the post-transcriptional level (59). These data indicate that there is an antagonistic effect between RBM4 and PTBPs on the utilizing of SRSF3 exon 4.

Moreover, SLU7, a another critical splicing factor for the $3^{\prime}$ splice site selection (60), is also reported to modulate SRSF3 splicing; that is, the knockdown of SLU7 induces an increase in the ratio of SRSF3 Iso2/Iso1, while SLU7 overexpression has the opposite effect (44). Further study found that SLU7 can inhibit the increasing of SRSF3-TR proteins at two levels: during the regulation of SRSF3 splicing and during the expression of miR-17 that can target SRSF3-Iso2 and promote its degradation (44).

hnRNP L is a multi-functional splicing factor that is active in a series of RNA processes, including chromatin modification, mRNA export, mRNA stability, alternative splicing, poly $(\mathrm{A})$ site selection, and translational regulation (61). It was found that hnRNP L knockdown reduced the expression of SRSF3 in many cancer cell lines (62). The overexpression of hnRNP L has been found to promote SRSF3 expression in caner cells. In addition, the expression levels of hnRNP L were found to positively correlate, moderately, with the expression levels of SRSF3 in OSCC tissues. hnRNP L expression correlates with SRSF3 expression in OSCC tissues (62).

\section{Regulation by $\mathrm{Wnt} / \boldsymbol{\beta}$-Catenin Signaling}

$\mathrm{Wnt} / \beta$-catenin signaling is a highly conserved pathway in eukaryotic cells, its activation depends on the involvement of $\beta$ catenin in signal transduction (63). Generally, free cytoplasmic $\beta$-catenin is translocated to the nucleus to bind to the T-cell factor/lymphocyte enhancer factor (TCF/LEF), resulting in the displacement of co-repressors and recruitment of additional coactivators for Wnt target genes (64). SRSF3 is determined as a target of $\beta$-catenin/TCF4 signaling, and both the transcript and protein levels of SRSF3 are regulated by the activity of $\beta$-catenin (65-68). The isolated SRSF3 gene promoter makes responds to influence of $\beta$-catenin/TCF4 signaling. Further study demonstrates that an increasing of SRSF3 protein levels mediated by the $\beta$-catenin/TCF4 pathway is sufficient to regulate alternative splicing decisions $(67,68)$.

\section{Regulation by DARPP-32}

DARPP-32 (dopamine and cyclic adenosine monophosphateregulated phosphoprotein, $\mathrm{Mr}$ 32000) is a master molecular regulator in neurons that receive the neurotransmitter dopamine (69). It was found that stable overexpression of DARPP-32 enhanced SRSF3 protein level, while endogenous DARPP-32 knockdown significantly decreased SRSF3 protein expression. Interestingly, overexpression or knockdown of endogenous DARPP-32 had no significant effects on SRSF3 mRNA levels. Further experiments in immunoprecipitation 
and immunoblotting showed the co-existence of DARPP32 and SRSF3, and DARPP-32 could prolong the SRSF3 protein half-life $(20.5 \mathrm{~h})$ compared with that of the control (14.9h). Finally, DARPP-32 was proved to stabilize the SRSF3 protein by regulating its ubiquitination, which subsequently triggered the degradation of SRSF3 protein. This indicates that DARPP-32 positively regulates SRSF3 protein levels through a post-translational mechanism (70).

\section{Regulation by PLC $\beta 1$}

PLC $\beta 1$ (phospholipase $C$ beta 1) acts an significant role in the intracellular transduction of multiple extracellular cell signals with the assistant of calcium. An increasing evidences show that PLC $\beta 1$ is the main isoform of PLC locates in the nucleus in a phosphoinositide-specific manner (71). The overexpression of PLC $\beta 1$ causes the decrease of SRSF3 protein level. Further study found that SRSF3 could interacted with nuclear PLC $\beta 1$ at the nuclear level. These results suggest that SRSF3 is a novel target gene of the nuclear phosphoinositide-specific PLC $\beta 1$ signaling and creates new stages for the metabolism of nuclear inositol lipid (72).

\section{Regulation by CircSMARCA5}

circSMARCA5, an exonic circRNA, was found to be in high numbers in the human brain, and was proved to act as a regulator of SRSF3 splicing. In glioblastoma biopsies, circSMARCA5 was markedly downregulated comparing with the normal brain tissues $(73,74)$. circSMARCA5 overexpressing was able to increase the expression levels of SRSF3 isoform including exon 4 (SRSF3 Ex4) in cells. Consistently, a significant increasing of SRSF3 isoform without exon 4 (SRSF3 No Ex4) in biopsies exhibits a observably downregulation of circSMARCA5. Precipitously, SRSF3 Ex4 levels was also upregulated in biopsies, consistent with the data obtained from the circSMARCA5 overexpression cells. This indicates that there is a positively correlation between the SRSF3 Ex4/SRSF3 No Ex4 ratio and the expression levels of circSMARCA5 in glioblastoma biopsies (74).

\section{SRSF3 IN CANCER}

Despite the above-mentioned regulatory mechanisms for maintaining constant SRSF3 levels, many environmental factors can still influence the expression of SRSF3, such as human papillomavirus (HPV) (75), hepatitis B virus-encoded X protein $(\mathrm{HBx})(76)$, hypoxia $(29,77)$, low $\mathrm{pH}(78)$, carcinogen DMBA (79), caffeine (80), amiodarone (81), small molecule amiloride (82), digoxin (83), and theophylline (84). Thus, the aberrant expression of SRSF3 closely relates to the occurrence, development, prognosis, and treatment response of diseases, including cancer.

\section{Aberrant Expression of SRSF3 in Cancer}

SRSF3, as a potential diagnostic and prognostic biomarker, is upregulated in multiple types of human cancer, including breast cancer (85-88), ovarian cancer $(26,89)$, retinoblastoma (90, 91), head and neck cell squamous $(62,79,92)$, glioblastoma (GBM) (23), gastric cancer (36), colorectal cancer (CRC) (33,
36, 93), cervical cancer (94), and hepatocellular carcinoma (HCC) $(30,95)$. Moreover, studies show SRSF3 upregulation not only in epithelial cancers, but also in mesenchymal tumors, as Table 1 shows (11). In addition, the single nucleotide polymorphisms (SNPs) of SFRS3 were also associated with tumor progression and prognosis. Studies report that three SNPs in SRSF3 (rs2145048, rs1406945, and rs9394364) were found in breast cancer, which may be associated with susceptibility to cancer. Among these SNPs, the C allele of rs1406945 was found to be related with increased breast cancer risk, the A allele of rs9394364 was associated with a marginally lower breast cancer risk, and the A allele of rs2145048 was associated with a lower breast cancer risk (104). Interestingly, there are contradictory reports on the expression and function of SRSF3 in colorectal cancer. It was reported that SRSF3 and hnRNPA1 indicated the two highest increasing incidences (88 and 74\%, respectively), for colorectal cancer (97). There is no statistically significant correlation between the mRNA levels of SRSF3 and the histological features, lymph node metastasis, or tumor node metastasis (TNM) stage (97). However, it was found that SRSF3 was significantly upregulated in a normal colon, but it had different expression levels (negative to strong) in colorectal cancer tissues $(33,93)$. SRSF3 presents a gradual expression loss during cancer progression. SRSF3 is negative or weakly positive expressed in $80 \%$ patients with metastatic stage IV, which was markedly related to poor survival in colorectal cancer (93). Similar to colorectal cancer, the expression and function of SRSF3 are also contradictory in liver diseases. In mice, SRSF3 overexpression was proved to be crucial for maintaining hepatocyte metabolic function and differentiation $(20,105)$. The deletion of SRSF3 damages the maturation and metabolism of hepatocyte during early adulthood in mice developed spontaneous HCC as they aged. In addition, SRSF3 may play a role in the prevention of hepatic carcinogenesis by regulating splicing to inhibit fibrosis, mitogenic splicing, and epithelial-mesenchymal transition (EMT) (105). In line with these results, hepatic SRSF3 expression was decreased in mouse models of non-alcoholic fatty liver disease (NAFLD) and non-alcoholic steatohepatitis (NASH). Thus, the avoidance of SRSF3 degradation in mice can protect them from hepatic steatosis, fibrosis, and inflammation, to some extent (98). However, SRSF3 expression presented no changes in mouse models of PTEN-deficient HCC and DENinduced HCC (95). In human HCC, it was reported that SRSF3 expression was either downregulated or the protein was mislocalized (105), whereas Wang found a significant increasing expression of SRSF3 in human HCC tumors (30, 95), which emerged progressive upregulation from a normal liver to a cirrhosis/fibrosis liver, and ultimately HCC (30). In addition, upregulation of isoforms SRSF3 was also found in these tissues $(30,95)$, which might enhance the development of HCC by regulating splicing of SRSF3 targets (30). Consequently, it is likely that SRSF3 presents low expression and tumorsuppressor activity in mouse liver disease, while it shows high expression and acts as an oncogene in human HCC, suggesting its role as an unfavorable prognostic predictor in HCC. Unexpectedly, there is a positive links between SRSF3 
TABLE 1 | Clinical features, cell functions and related genes associated with upregulation of SRSF3 in human cancer.

\begin{tabular}{|c|c|c|c|c|c|c|c|}
\hline Tumor type & Expression & Role & Clinic relevance & Cell line & Function & Related gene & References \\
\hline Glioblastoma & Upregulated & Oncogene & High tumor grades & $\begin{array}{l}\text { U87, GSC83, } \\
\text { GSC528, GSC23 }\end{array}$ & $\begin{array}{l}\text { Tumorigenicity, } \\
\text { proliferation, } \\
\text { cell growth, } \\
\text { self-renewal }\end{array}$ & ETV1, NDE1 & (23) \\
\hline Ovarian cancer & Upregulated & Oncogene & $\begin{array}{l}\text { Poor clinical } \\
\text { parameters, poor } \\
\text { survival }\end{array}$ & $\begin{array}{l}\text { A2780, IGROV1, } \\
\text { SKOV3 }\end{array}$ & $\begin{array}{l}\text { Drug resistance, } \\
\text { apoptosis, } \\
\text { metastasis }\end{array}$ & Bcl-2, MRP1, CD44 & $(26,89,96)$ \\
\hline Colorectal cancer & $\begin{array}{l}\text { Upregulated or } \\
\text { gradual loss }\end{array}$ & Oncogene & $\begin{array}{l}\text { No significance (based } \\
\text { on protein level); } \\
\text { advanced } \\
\text { cancer progression, } \\
\text { poor survival (based } \\
\text { on protein level) }\end{array}$ & $\begin{array}{l}\text { HCT-116, HT-29, } \\
\text { KM12C, CaCo-2, } \\
\text { HCT-8, Colo205, } \\
\text { HCT-116, DLD-1, } \\
\text { WiDr, KM12SM, } \\
\text { SW480 }\end{array}$ & $\begin{array}{l}\text { Tumorigenicity, } \\
\text { proliferation, } \\
\text { metastasis, } \\
\text { adhesion, } \\
\text { invasion, } \\
\text { apoptosis }\end{array}$ & $\begin{array}{l}\text { RBM4, MAP4K4, } \\
\text { JNK1, E-cadherin, } \\
\text { N-cadherin, } \beta \text {-catenin, } \\
\text { MCC, PKM, E2F1/7, } \\
\text { vimentin, } \\
\text { cyclins (D1/D3/E1), } \\
\text { HIPK2, Bcl-2 }\end{array}$ & $\begin{array}{c}(11,28,33,36 \\
39,59,65,93, \\
97)\end{array}$ \\
\hline $\begin{array}{l}\text { Hepatocellular } \\
\text { carcinoma }\end{array}$ & Upregulated & Oncogene & $\begin{array}{l}\text { Positive associated } \\
\text { with HBV-associated } \\
\text { HCC in patients with } \\
\text { higher AFP levels; } \\
\text { poor overall survival; } \\
\text { longer overall survival } \\
\text { in patients with HCC } \\
\text { resection }\end{array}$ & $\begin{array}{l}\text { Bel-7404, HepG2, } \\
\text { Bel-7402, } \\
\text { MHCC97H, } \\
\text { MHCC97L, } \\
\text { HepG2.2.15 }\end{array}$ & $\begin{array}{l}\text { Colony formation; } \\
\text { proliferation, } \\
\text { migration; } \\
\text { invasion }\end{array}$ & $\begin{array}{l}\text { NEDD8, ARHGEF2, } \\
\text { 14-3-3 } \beta \text {, Ras, Foxo4, } \\
\text { cCDC50S, HBX }\end{array}$ & $\begin{array}{c}(11,30,76,95 \\
98)\end{array}$ \\
\hline Osteosarcoma & Upregulated & Oncogene & Unknown & U2OS, Rh30 & $\begin{array}{l}\text { Colony formation, } \\
\text { transformation, } \\
\text { proliferation, } \\
\text { migration, } \\
\text { invasion cell cycle, } \\
\text { apoptosis }\end{array}$ & $\begin{array}{l}\text { CCND1, } \\
\text { miR-1908-5p, REST, } \\
\text { miR-132-3p, } \\
\text { miR-212-3p, YAP1, } \\
\text { NF-кB, NKIRAS2, } \\
\text { IL-3; PDCD4 }\end{array}$ & $\begin{array}{c}(11,36,39,52 \\
99,100)\end{array}$ \\
\hline Breast cancer & Upregulated & Oncogene & $\begin{array}{l}\text { High tumor grade, } \\
\text { poor tumor } \\
\text { progression and } \\
\text { prognosis }\end{array}$ & $\begin{array}{l}\text { MDA-MB231, } \\
\text { SKBR3 }\end{array}$ & $\begin{array}{l}\text { Transformation, } \\
\text { proliferation, } \\
\text { apoptosis, } \\
\text { metastasis, } \\
\text { cell cycle }\end{array}$ & $\begin{array}{l}\text { p53; TDP4; PAR3; } \\
\text { NUMB; HER2 }\end{array}$ & $(11,84-88,101)$ \\
\hline Gastric cancer & Upregulated & Oncogene & No significance & & & & $(11,97)$ \\
\hline Cervical cancer & Upregulation & Oncogene & $\begin{array}{l}\text { Increased diagnostic } \\
\text { accuracies } \\
\text { comparable to CEA }\end{array}$ & Hela, C33A, CaSki & $\begin{array}{l}\text { Colony formation, } \\
\text { proliferation, } \\
\text { apoptosis, } \\
\text { migration, } \\
\text { invasion, } \\
\text { cell cycle }\end{array}$ & $\begin{array}{l}\text { p53, REST, } \\
\text { miR-132-3p, PLK1, } \\
\text { CCND1, FoxM1, } \\
\text { miR-212-3p, YAP1, } \\
\text { Cdc25B, IL-3 }\end{array}$ & $\begin{array}{c}(11,84,94,99 \\
100)\end{array}$ \\
\hline $\begin{array}{l}\text { Head and neck } \\
\text { squamous cell } \\
\text { carcinoma }\end{array}$ & Upregulated & Oncogene & $\begin{array}{l}\text { high tumor grade, } \\
\text { worse lymphatic } \\
\text { metastasis, } \\
\text { poor survival }\end{array}$ & $\begin{array}{l}\text { CAL27, FaDu, } \\
\text { SCC-9 }\end{array}$ & $\begin{array}{l}\text { Autophagy, cell } \\
\text { growth }\end{array}$ & $\begin{array}{l}\text { BECN1, FoxO1, Snail, } \\
\text { p65, N-cadheri, } \\
\text { hnRNP L }\end{array}$ & $(62,79,92,102)$ \\
\hline Retinoblastoma & Upregulated & Oncogene & Unknown & Unknown & Unknown & Unknown & $(90,91)$ \\
\hline $\begin{array}{l}\text { Others cancers } \\
\text { (lung, bladder, } \\
\text { kidney, skin, } \\
\text { thyroid) }\end{array}$ & Upregulated & Oncogene & Unknown & $\begin{array}{l}\text { JSC-1, BCBL1, } \\
\text { SUDHL-6, T24, } \\
\text { 253J-BV, PC3, } \\
\text { KATOIII, A375, } \\
\text { NUGC3, MKN7 }\end{array}$ & $\begin{array}{l}\text { proliferation, } \\
\text { apoptosis }\end{array}$ & MDM2/4, p21, ВBC3 & $(11,24,33)$ \\
\hline $\begin{array}{l}\text { Acute myeloid } \\
\text { leukemia }\end{array}$ & Downregulated & Oncogene & Unknown & Unknown & Unknown & Caspase-8 & (98) \\
\hline Renal cancer & Downregulated & Oncogene & Unknown & $786-0$ & Proliferation & Unknown & $(11,103)$ \\
\hline
\end{tabular}

upregulation and longer overall survival in patients with HCC resection (95).

In contrast to the upregulation of SRSF3 in the above tumors, the expression of SRSF3 mRNAs was significantly decreased in acute myeloid leukemia (103) and renal cancer (106), as shown in
Table 1. However, it was also identified as an oncogene in these two types of cancers. Nonetheless, the correlation between SRSF3 expression and carcinogenesis and the progression of these cancers, such as histological features, lymph node metastasis, TNM stage, or overall survival, remains to be studied. 


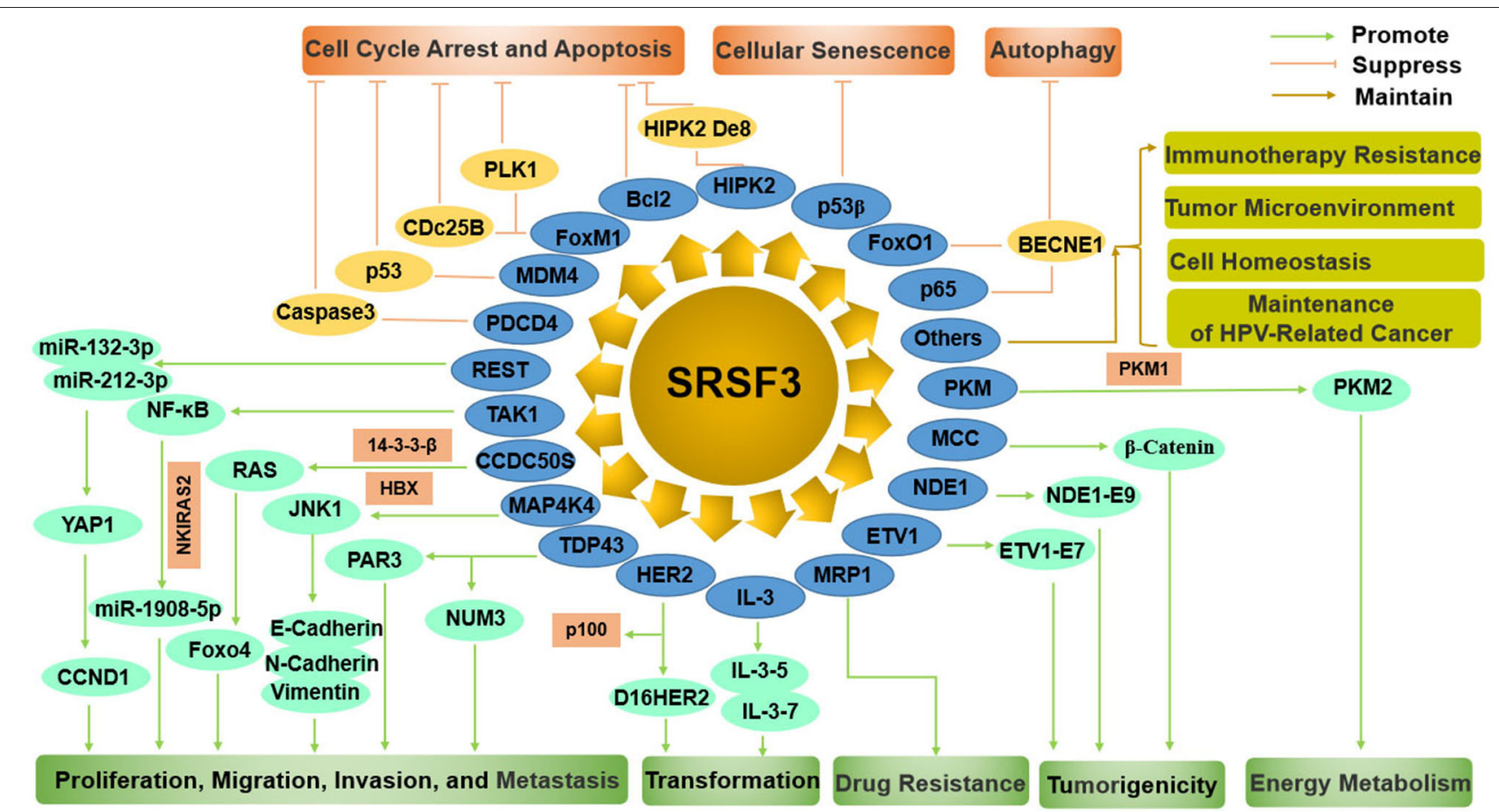

FIGURE 4 | The comprehensive mechanism of SRSF3 functions as an oncogene by regulating multiple splicing targets in cancer cells. On the one hand, SRSF3 can enhance cell proliferation, migration, invasion, metastasis, transformation, drug resistance, tumorigenesis, and energy metabolism. On the other hand, SRSF3 can inhibit cell cycle arrest, apoptosis, cellular senescence, and autophagy. SRSF3 is also involved in immunotherapy resistance, tumor microenvironment, cell homeostasis, and maintenance of HPV-related cancer.

\section{Pro-oncogenic Activity of SRSF3 by Regulating Cellular Biological Processes}

SRSF3 functions as an oncogene manipulating cell proliferation, cell cycle, apoptosis, migration, invasion, transformation, tumorigenesis, metastasis, drug resistance, autophagy, and cellular senescence by regulating many pathways, including p53, JNK, Ras, Wnt, HER2 signaling pathways, and miRNAs (Figure 4).

\section{Enhancement of Cell Proliferation, Migration, Invasion, and Metastasis}

SRSF3-silencing inhibits the proliferation, migration, invasion, and metastasis of tumor cells $(33,39,52,99)$. It was reported that SRSF3 affected the expression levels of miR-132-3p and miR-212-3p, including both their primary form and their mature form, by controlling RE1-silencing transcription factor (REST) in cancer cells (99). miR-132-3p and miR-212-3p were found to inhibit the malignant phenotypes of cancer cells by repressing Yes-associated protein 1 (YAP1) and its downstream gene CCND1 (Cyclin D1), which demonstrates that SRSF3 gives malignant characteristics to cancer cells by SRSF3/REST/miR-132-3p (miR-212-3p)/YAP1/CCND1 axis (99). Beside miR-132-3p and miR-212-3p, SRSF3 may also upregulate the expression of miR-1908-5p by enhancing NF-кB transactivation (52). Interestingly, miR-1908-5p in turn could downregulate NF- $\kappa \mathrm{B}$ activation by binding to an inhibition

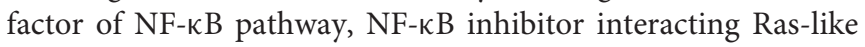

2 (NKIRAS2), resulting in elevating cancer cell proliferation and metastatic potential (52). These data suggest that SRSF3 enhances the malignant characterization of cancer cells via the SRSF3/miRNA axis.

CCDC50, as a tyrosine-phosphorylated protein, is required for cell survival as it inhibits the NF- $\kappa \mathrm{B}$ or p53 mediated apoptotic pathway $(107,108)$. CCDC50S, as a truncated oncogenic splice variant, was highly expressed in HCC and significantly correlated with progression and predicts poor survival of patients (76). SRSF3 was reported to directly bind to CCDC50S mRNA for its maintenance in the cytoplasm, resulting in the promotion of HCC progression by increased activation of Ras/forkhead box protein O4 (Foxo4) signaling (76). Contrarily, SRSF3 was mediated by the interaction of $\mathrm{HBx}$ and $14-3-3 \beta$, which demonstrated the existence of the $\mathrm{HBx} / 14$ $3-3 \beta / S R S F 3 / C C D C 50 S / F o x o 4$ axis in oncogenic progression of HCC (76).

Mitogen-activated protein 4 kinase 4 (MAP4K4) belongs to the STE20/MAP4K family that content a serine/threonine kinase domain, and is involved in cytoskeletal rearrangement and migration by regulating the MAPK/ERK kinase cascade (109). It was reported that alternatively spliced MAP4K4 variants showed differential influences on the EMT process, which is a critical process for the migration and invasion of cancer cells (59). SRSF3 could modulate the usage of MAP4K4 exon $16^{\prime}$ in a sequence specific manner, while the inclusion of SRSF3 exon $4^{\prime}$ could be enhanced by RBM4 in colorectal cancer cells (59). These date 
suggest that the RBM4-SRSF3-MAP4K4 axis manipulate the metastasis of cancer cells through the EMT process.

TDP43 (TAR DNA-binding protein), is a highly conserved and an important splicing regulator that controls gene expression. TDP43, as a major splicing regulator in triplenegative breast cancer (TNBC), is associated with poor prognosis in TNBC progression (86). And TDP43 overexpression could significantly enhance the proliferation and malignancy of mammary epithelial cell (86). In coordination with SRSF3, TDP43 can alter most splicing events, including $P A R 3$ and NUMB which play essential roles in cell proliferation and metastasis (86). Further study found that the TDP43/SRSF3/PAR3 axis regulated the metastasis of cancer cells, while the TDP43/SRSF3/NUMB axis controlled the proliferation of cancer cells (86).

\section{Enhancement of Cell Transformation}

HER2 (ErbB2) is a member of the erythroblastic oncogene B (ErbB) family of receptor tyrosine kinases. The overexpression of HER2 is associated with many aggressive tumors and a poor prognosis (110). HER2 possesses several splice variants that produce diverse proteins with various biological activities and functions in tumor development (111). SRSF3 was identified as an important splicing regulator of HER2. Loss of SRSF3 results in alterations in all splice variants of HER2. Especially, SRSF3 knockdown leads to a switch in HER2 mRNA splice variants from $\triangle 16 H E R 2$ to $p 100$ (101). Interestingly, the function of these two splice variants is contradictory. $\triangle 16 H E R 2$ is a highly tumorigenic factor that is likely to increase malignant transformation of breast cancer cells $(112,113)$, whereas $p 100$ is involved in the inhibition of tumor cell proliferation and oncogenic signals (114). That is, the overexpression of SRSF3 in tumors switches splicing variants of HER2 mRNA from $p 100$ to $\triangle 16$ HER2, leading to tumor progression (101).

Moreover, SRSF3 also controls the production of various splicing variants of interleukin enhancer binding factor 3 (ILF3) by the exclusion, inclusion, or 3' splice site selection of ILF3 exon 18 (100). SRSF3 knockdown expression produced aberrant isoform-5 and -7 of ILF3 in osteosarcoma cancer cells. Both isoform-5 and-7 can inhibit tumor cell proliferation, and isoform-7 can also induce cell apoptosis. SRSF3 overexpression in cancer cells has a positive association with the steady status maintenance of ILF3 isoform-1 and-2, which can promote cell proliferation and transformation (100).

\section{Enhancement of Drug Resistance}

The main obstacle to the improvement of prognosis is cancer chemotherapy resistance. The multidrug resistance protein 1 (MRP1) belongs to the ATP-binding cassette transporter subfamily linked to multidrug resistance $(115,116)$. MRP1 upregulation may trigger resistance to various chemotherapeutic drugs in ovarian cancer cell lines. MRP1 has also been reported to be involved in clinical drug resistance and to be of prognostic significance for predicting patients' response to chemotherapy (117-119). Interestingly, more MRP1 mRNA splice variants were found in ovarian tumors compared to the matched normal tissues (26). These variants can confer drug resistance even if they are not as effective as the full-length $M R P 1$. Further study found that SRSF3 overexpressed in ovarian tumors could result in more splicing variants of $M R P 1$ mRNA by increasing the identification of weak exons (26), which indicates that SRSF3 may be involved in the cancer chemotherapy resistance.

\section{Enhancement of Cell Tumorigenicity}

In patient-derived glioma stem-like cells (GSC), the increasing expression of SRSF3 causes the significantly improvement of cell proliferation, self-renewal, and tumorigenesis (23). More than 1,000 SRSF3-related AS events are identified by transcriptomic profiling, and they have a preference for exon skipping in cell mitosis genes. SRSF3 knockout results in the exon skipping at exon 7 of transcription factor ETS variant 1 (ETV1) to product ETV1-E7, leading to the enhancement of the proliferation and sphere formation ability of tumor cells. Further, the phosphorylation of ETV1-E7-encoded peptide could enhance the oncogenic activity of ETV1, promoting an ETV1-mediated oncogenic transcriptional program in GSCs. Moreover, SRSF3 knockout also induced the nudE neurodevelopment protein 1 (NDE1) gene to a mutually exclusive exon 9' taking the place of the terminal exon 9, resulting in the production of isoform-specific function of NDE1 (NDE1-E9) in mitotic spindle formation that is important for tumor cell growth (23).

Similarly, in $\mathrm{CD}_{133^{+}}$colon cancer stem like cells (CSLCs), SRSF3 was overexpressed and acted a part in the oncogenicity of colon CSLCs by regulation of the Wnt/b-catenin pathway (65). SRSF3, as a novel target of the Wnt/b-catenin pathway, was upregulated by Wnt pathway activation in $\mathrm{CD}_{13}{ }^{+}$colon cancer cells (68). SRSF3 exerts a powerful negative effect on the expression of the mutated in colorectal cancer (MCC) protein expression, which is significantly upregulated in various CRC cell lines. Interestingly, the MCC protein could interact with $\beta$ catenin, resulting in the inhibition of Wnt signaling $(65,120)$, suggesting that SRSF3 may be involved in the Wnt pathway modulation, resulting in forming positive feedback relationships among the Wnt/b-catenin pathway, SRSF3, and MCC.

\section{Enhancement of Energy Metabolism}

Alternative splicing of the pyruvate kinase M (PKM) can produce the pyruvate kinase muscle 2 (PKM2) isoform and promote aerobic glycolysis and tumor growth (121). PKM is controlled by mutually beneficial effects on the two mutually exclusive exons 9 and 10 in cancer cells, resulting in the repression of exon 9 and the activation of exon 10. SRSF3 was found to activate exon 10 , mediating changes in glucose metabolism (22). Loss of SRSF3 in human colon cancer cells induces an increasing in the ratio of PKM1/PKM2, leading to a metabolic shift from glycolysis toward oxidative phosphorylation. Moreover, the SRSF3 silenced cells causes markedly inhibition of cell growth and autophagy (33). These findings indicate that SRSF3 acts as a critically positive regulator for PKM mRNA splicing and cancer-specific energy metabolism.

\section{Inhibition of Cell Cycle Arrest and Apoptosis}

A decreased level of SRSF3 could induce cell apoptosis and reduce cell proliferation in SW480 (human colon 
adenocarcinoma) and U2OS (human osteosarcoma) cells (39). Microarray analyses shows that SRSF3 silencing causes the upregulation of 381 genes and the downregulation of 274 genes in U2OS cells. Among them, A number of genes are related to the apoptotic and anti-apoptotic processes, including PDCD4, who was the most affected (39). PDCD4 was reported to be a tumor suppressor that was involved in cellular processes, such as antiproliferation, apoptosis, and antimetastasis in various cancer cells $(122,123)$. As mentioned above (functions of SRSF3), SRSF3 was further proved to participate in alternative splicing and the export and translation of PDCD4 mRNA, leading to the downregulation of the PDCD4 protein $(36,39)$. SRSF3 and PDCD4 knockdown could prevent tumor cell apoptosis with decreased Caspase-3 activation and decreased amount of fragmented chromosomal DNA. These results indicate that the effects of PDCD4 on cell proliferation and apoptosis might be dependent on the expression levels of PDCD4 (39).

The p53 tumor suppressor gene is a nuclear transcription factor that transmits signals arising from many types of genotoxic or cellular stress, such as DNA damage, hypoxia, and nucleotide deprivation, to the target genes and related factors that induce cell cycle arrest, cell death, or cellular senescence (124). The tumorsuppressor function of $\mathrm{p} 53$ can be induced or inhibited by many other genes, including SRSF3. Reportedly, the inactivation of SRSF3 with the inclusion of MDM4 exon 6, can stimulate p53 activation (24). SRSF3 was found to be necessary for MDM4 exon 6 inclusion and the growth of melanoma. In embryonic tissues and cancers, the enhancement of exon 6 inclusion can significantly upregulate the levels of MDM4 protein to inhibit the tumor-suppressor function of p53 $(125,126)$. In human cancers, an increasing expression of MDM4 is promoted by a non-sense-mediated, decay-targeted isoform of MDM4 (MDM4$S)$ by enhancing exon 6 inclusion $(127,128)$. The knockdown of SRSF3 leads to MDM4 downregulation, resulting in the activation of p53 pathway as well as its target genes, such as $p 21, M D M 2$, and $B B C 3$ (24). Consequently, cell growth is markedly decreased, while cell death is increased in SRSF3 silencing cells.

The increased expression of SRSF3 overexpression in cancer cells causes the improvement of cell cycle performance by influencing the expression levels of $\mathrm{G} 2 / \mathrm{M}$ transition regulators, including Forkhead box transcription factor M1 (FoxM1), PLK1, and Cdc25B. Conversely, SRSF3 silencing causes G2/M arrest, growth retardation, and apoptosis (11). Further study documented that SRSF3 silencing also caused G1 arrest in combination with the downregulation of several G1/S checkpoint regulators, including cyclins (D1, D3, and E1), E2F1, and E2F7, which likely impaired G1-to-S-phase progression (28). In addition, SRSF3 silencing could induce cell apoptosis by reduction of Bcl-2 $(28,96)$. Moreover, SRSF3 silencing changed the alternative splicing of homeodomain-interacting protein kinase2 (HIPK2), resulting in the production of HIPK2 De8 isoform which facilitated the cell apoptosis by phosphorylating p53 at Ser46 (28). These results expose the critical role of SRSF3 in the regulation of G1-S and G2-M cycle performance, Bcl-2 expression, and HIPK2-mediated cell apoptosis (28).

\section{Cellular Senescence Inhibition}

Cellular senescence, an irreversible proliferation arrest, is identified as another endogenous mechanism that represses tumorigenesis in company with cell death programs (129-131). Endogenous SRSF3 knockdown could induce cellular senescence, and upregulate the expression of $p 53 \beta$ (an alternatively spliced isoform of $p 53$ ) to trigger p53-mediated senescence (27). p53 silencing restores SRSF3-knockdown-induced cellular senescence in part, suggesting that SRSF3 plays a role in the initiation of p53-mediated cellular senescence. Further, SRSF3 was found to bind to an alternatively-spliced exon of $p 53 \beta$ mRNA in sequence-dependent manner. (27), suggesting that SRSF3 is an inhibitor in p53-mediated cellular senescence.

\section{Inhibition of Autophagy}

Autophagy is an evolutionarily conserved cellular catabolic process. SRSF3 can act as an autophagy suppressor $(33,102)$. SRSF3 knockdown significantly induces autophagy with an increased LC3B-II/LC3B-I ratio, whereas the overexpression of SRSF3 inhibits autophagy induction with an decreased ratio of LC3B-II/LC3B-I. Moreover, SRSF3 knockdown plus autophagic degradation inhibitor chloroquine could enhance the accumulation of LC3B-II, suggesting that SRSF3 knockdown truly increases autophagic flux. The molecular mechanism is due to the suppression of the FoxO1 and p65 expressions as well as the transcriptional and protein levels of BECN1 (102).

\section{Others}

SRSF3-mediated alternative splicing was also reported to be associated with many other key genes, such as CD19 (132), CD44 $(68,133)$, and VEGF (78), and to be involved in other tumor related biology process, including the resistance to CART19 immunotherapy (132), tumor cell homeostasis (21), tumor microenvironment (low pH) (78), and the maintenance of HPVrelated cancer (134). With the growing knowledge on SRSF3 overexpression or knockout in human tissues and cells by highthroughput RNA-sequencing, more possible target genes and underlying mechanisms will be elucidated. It is even possible that the new data on cancer cells might differ from that on non-cancer cells, reflecting the oncogenic effects $v s$. tumor suppressor effects when expressed at high $v s$. low levels of SRSF3. Nevertheless, considerable efforts and in-depth studies are expected to provide more information on SRSF3 and their targets.

\section{Implications for Therapy}

The multifunctional characteristics of SRSF3 highlight it as a novel splicing regulator for gene expression and cell homeostasis. Given the crucial roles of alternative splicing in cancer biology, pharmacological modulation of SRSF3-mediated splicing may represent an important therapeutic strategy. Indeed, thus far, SRSF3 has been evidenced to associate with the antitumor function of some drugs in the development of targeted therapeutics for the treatment of cancer, as shown in Figure 5.

Caffeine, a 1,3,7-trimethylxanthine derivative, is a potential anticancer drug that inhibits cell proliferation and induces apoptosis on various cancer cells in vitro and in vivo (135137). The alternative splicing of cancer-related genes is involved 
in caffeine-induced antitumor function, including p53, PKM2, and hypoxia-inducible factor- $1 \alpha / 2 \alpha$ (HIF- $1 \alpha / 2 \alpha)(80,138-140)$. In cervical cancer cells, caffeine regulates cell-cycle arrest and cell apoptosis by decreasing SRSF3 expression that modifies the expression of various splice variants of $p 53$, including reducing $p 53 \alpha$ expression and inducing $p 53 \beta$ expression. In addition to $\mathrm{p} 53$-dependent functions, multiple genes involved in the EMT and hypoxic conditions are all found to be regulated by SRSF3 (80). Theobromine (1,3-dimethylxanthine), a metabolite of caffeine, may also downregulate SRSF3 expression by switching $p 53$ from $p 53 \alpha$ into $p 53 \beta$, which is similar to caffeine. Consequently, theophylline demonstrates antitumor roles via inducing cellular apoptosis, senescence, and decreasing colony formation. Moreover, theophylline could synergistically enhance caffeine-induced cell death (84). A similar switch of $p 53$ splicing from $p 53 \alpha$ to $p 53 \beta$ is induced by digoxin, a popular cardiac glycoside identified as a potential anticancer drug $(83,141)$. Similar to caffeine, digoxin regulates $\mathrm{G} 2 / \mathrm{M}$ arrest, DNA damage, and cell apoptosis via p53-dependent pathway in cervical cancer cells by reducing both SRSF3 expression and increasing expression of $p 53 \beta$ isoform (83).

Amiodarone is an anti-arrhythmic drug commonly used to block several types of myocardial potassium channels in arrhythmia and atrial fibrillation $(142,143)$. Amiodarone also sensitizes tumor cells in response to chemotherapy $(144,145)$. It has been proved that the mechanism of action of amiodarone may be similar to that of caffeine or digoxin, it also regulates senescence through the SRSF3-p53 pathway $(20,27,146,147)$. Amiodarone could induce cellular reactive oxygen species (ROS) and suppressed cell survival in cervical cancer cells. Moreover, amiodarone is found to strengthen the effectiveness of caffeine and digoxin on cell toxicity (81). Amiodarone also reduces the
SRSF3 gene and protein expression. However, it accumulates the population of SRSF3-PTC without the switch of $p 53$ splicing from $p 53 \alpha$ to $p 53 \beta$ via the SRSF3 downregulation, suggesting that amiodarone causes cancer cell death in a p53independent manner. Interestingly, amiodarone can work in coordination with caffeine and digoxin on the expression of $p 53$ alternative splicing isoforms from $p 53 \alpha$ into $p 53 \beta$ via decreasing SRSF3 (81). Amiloride, 3,5-diamino-6-chloro-N(diaminomethylene) pyrazinecarboxamide monohydrochloride, is a prototype intracellular $\mathrm{pH}(\mathrm{pHi})$ modulator medicine widely used for clinically treating in edema and hypertension depending on its sodium transport and humoral steady-state effects (148). In many solid tumor and leukemic cells in humans, amiloride was discovered to present an antitumor ability that decreased cell migration and invasion, arrested cell cycle, enhanced apoptosis, and caused severe DNA damage, and, ultimately, cell death (82). Mechanically, amiloride was proved to "normalize" the mRNA splicing of BCL-X, HIPK3, and RON/MISTR1 by the decreased expression of SRSF3 and some other SR proteins in human HCC cells. Further, it was found that amiloride regulated SRs by downregulating kinases and upregulating phosphatases involved in phosphorylation pathways of SRs (82). However, further study is required to investigate whether the various antitumor drugs mentioned above regulate SRSF3 in a direct or indirect fashion.

\section{DISCUSSION}

The rising role of alternative splicing and splicing-related factors in cancer has opened doors not only for the understanding of tumor occurrence and progression but also for the development of new targeted therapy. In reality, splicing-related factors

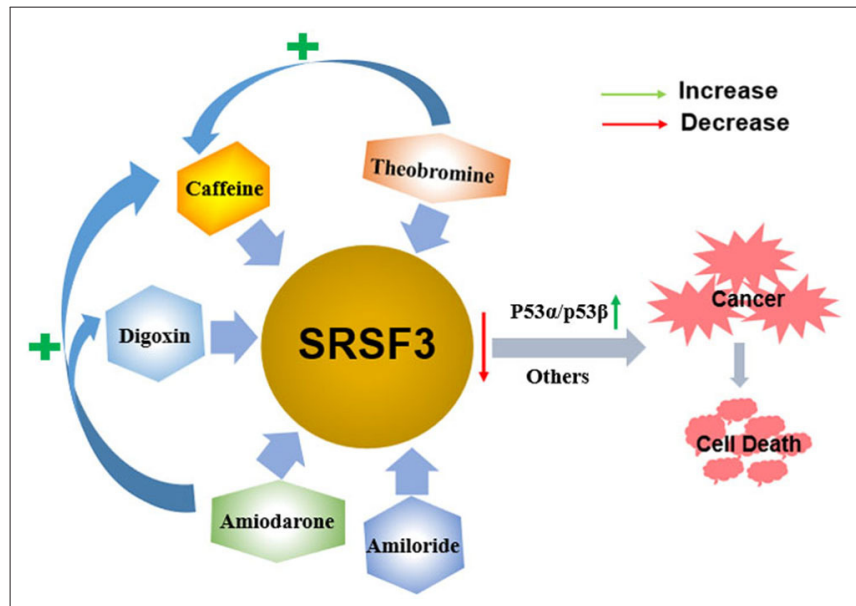

FIGURE 5 | The antitumor function of some drugs via decreasing the expression of SRSF3. Caffeine, digoxin, amiodarone, amiloride, and theobromine induce the apoptosis of cancer cells by decreasing the expression of SRSF3 and its downstream signaling cascade, including inducing the switch of $p 53$ splicing from $p 53 \alpha$ to the $p 53 \beta$ isoform. Moreover, theophylline and amiodarone could enhance caffeine-induced cell death, and amiodarone could also enhance the efficacy of digoxin.

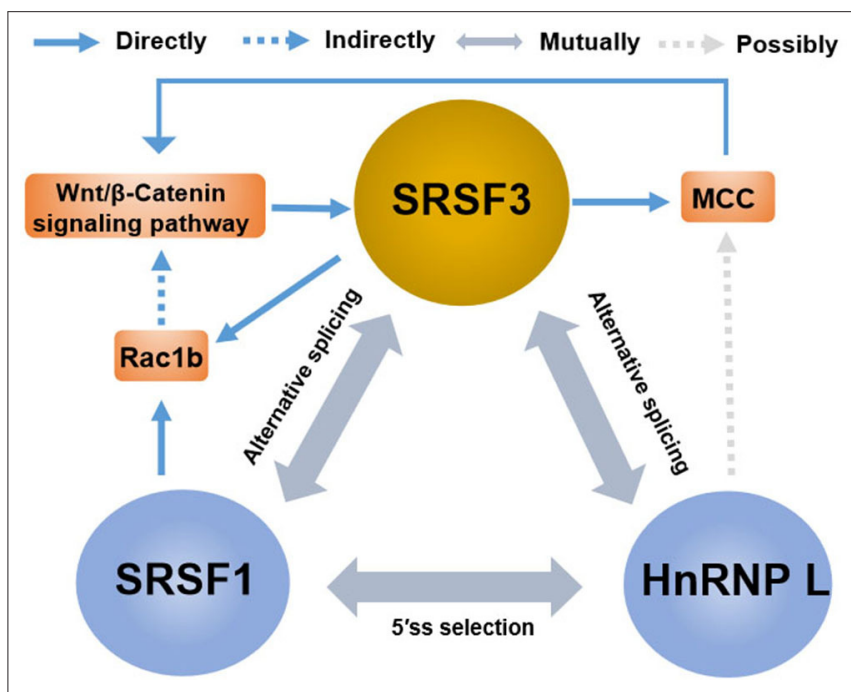

FIGURE 6 | The crosstalk between SRSF3 and other splicing regulators in the regulation of gene expression. There are antagonistic effects among SRSF3, SRSF1, and HnRNP L on alternative splicing or 5'ss selection, involving the key genes or signaling pathways, such as the $\mathrm{Wnt} / \beta$-catenin pathway, MCC protein, and Rac1b. 
can act either as survival-promoting factor that reduce druginduced apoptosis or, contrarily, as potentiating the proapoptotic effects of chemotherapeutics (149). SRSF3 can be considered as a potential molecular switch that regulates many biological processes in cancer cells, enabling sensitization of cancer cells to therapeutic treatments. Notably, the contribution of SRSF3 to the regulation of key genes goes far beyond the splicing reaction and involves all aspects of gene expression, while also cooperating with other splicing regulators. For instance (Figure 6), in addition to the induction of the MCC protein, $\beta$-catenin/TCF4-induced SRSF3 expression decreased Rac1b expression in colorectal tumor cells by increasing skipping of alternative exon 3b (67). Interestingly, Rac1b, an alternative splicing variant of Rac1, is an oncoprotein increased in the subgroup of colorectal tumors and is necessary to maintain the viability of tumor cells $(150,151)$. These results may support the view that SRSF3 causes the overall change of gene expression to maintain cell homeostasis (21). This may also explain the fact that SRSF3 presents a high expression in normal colons, and the loss of SRSF3 expression is significantly correlated with low survival rate and short disease-free survival time, especially in the early step of colorectal cancer (93). Moreover, in contrast to SRSF3 acting as a silencer of endogenous Rac1b splicing, SRSF1 was found to increase the inclusion of alternative exon $3 \mathrm{~b}$, acting as an enhancer of Raclb splicing (67). Meaning, SRSF1 and SRSF3 exhibits antagonistic effects on alternative splicing of Rac1b, which is in accordance with that of SRSF1 and SRSF3 having antagonistic effects on mutual splicing events (57). In addition to SRSF1, hnRNP L is the other splicing factor whose alternative splicing is regulated by SRSF3, while hnRNP $\mathrm{L}$ also regulates the expression of oncogene SRSF3 $(62,92)$. Contrarily, hnRNP L and SRSF1 also have an antagonistic effect on $5^{\prime}$ SS selection (152). This indicates that multiple SR members share target genes and the redundancy of functions of multiple SR proteins. This also indicates that there is compensatory regulation of expression in multiple SR protein members, which is very relevant to the effectiveness of multiple drugs on SRSF3 action as there might be compensatory upregulation of other SR protein members after SRSF3 inhibition. Moreover, some RNA modification regulators are also involved in the regulation network of splicing factors, including the N6-methyladenosine (m6A)-binding protein YTHDC1 (YTH domain containing 1). YTHDC1 can promote exon inclusion of targeted mRNA by recruiting SRSF3 while blocking SRSF10, which expands the potential utility of m6A modification mRNA $(153,154)$. In a word, the mutual regulation of splicing factors is a complex and important process for expression in target genes. Thus, future study is needed for the exploration of the relationship between SRSF3 and other mRNA related factors, including that of other spliceosome-associated proteins, splicing regulatory factors, and transcriptional factors.

In terms of the importance of splicing factors in cancer pathology, emerging studies focus on the discovery of new small compounds in tumor suppression, targeting spliceosome elements (149). SRSF3 downregulation is associated with cell death by the treatment of caffeine, digoxin, theophylline, amiodarone, and amiloride in cancer cells (80-83). In addition, small inhibitors of kinases have been identified as potential chemotherapeutics to angiogenesis, including BE-13793C (155), TG003 (156), and SRPIN340 (157); it will be interesting to evaluate their impact on SRSF3. Similar to other SR proteins, SRSF3 is phosphorylated by kinases including topoisomerase I, the SR protein kinase (SRPK) family, and the CDC2like kinase (CLK) family (24, 158-160), with affecting SR protein subcellular localization, binding to substrate mRNA and interacting with other proteins (161). Additionally, indole derivatives, such as benzopyridoindoles and pyridocarbazoles, is a recently discovered class of compounds that regulate splicing by altering the splicing activity of SR protein in company with the exonic splicing enhancer (ESE) (162). Indole derivatives have been proved to regulate splicing events that reversing the pro-metastatic splicing of Ron proto-oncogene mRNA (4, 163). Of course, the effects of SRSF3 in the functions of indole derivatives in tumor cells need extensive analysis. Nevertheless, investigating the molecular mechanisms governing SRSF3-dependent signaling will promisingly reveal new drug candidates and therapeutic targets for cancer treatment.

\section{AUTHOR CONTRIBUTIONS}

All authors contributed to the search of the literature and the writing of the manuscript, read, and approved the final manuscript.

\section{FUNDING}

This study was supported by the Innovative Talent Program of Qingdao (18-2-2-76-jch, 18-1-2-6-zhc), the National Natural Science Foundation of China (31671447, 91849209), and the Project of Shandong Province Higher Educational Science and Technology Program (J18KA2290).

\section{REFERENCES}

1. Cazzola M, Rossi M, Malcovati L, Associazione Italiana per la Ricerca sul Cancro Gruppo Italiano Malattie M. Biologic and clinical significance of somatic mutations of SF3B1 in myeloid and lymphoid neoplasms. Blood. (2013) 121:260-9. doi: 10.1182/blood-2012-09-399725

2. Will CL, Luhrmann R. Splicing of a rare class of introns by the U12-dependent spliceosome. Biol Chem. (2005) 386:71324. doi: 10.1515/BC.2005.084

3. Scotti MM, Swanson MS. RNA mis-splicing in disease. Nat Rev Genet. (2016) 17:19-32. doi: 10.1038/nrg.2015.3

4. Dvinge H, Kim E, Abdel-Wahab O, Bradley RK. RNA splicing factors as oncoproteins and tumour suppressors. Nat Rev Cancer. (2016) 16:41330. doi: 10.1038/nrc.2016.51

5. Das S, Krainer AR. Emerging functions of SRSF1, splicing factor and oncoprotein, in RNA metabolism and cancer. Mol Cancer Res. (2014) 12:1195-204. doi: 10.1158/1541-7786.MCR-140131 
6. Zhang J, Manley JL. Misregulation of pre-mRNA alternative splicing in cancer. Cancer Discov. (2013) 3:122837. doi: 10.1158/2159-8290.CD-13-0253

7. Wong J, Garner B, Halliday GM, Kwok JB. Srp20 regulates TrkB pre-mRNA splicing to generate TrkB-Shc transcripts with implications for Alzheimer's disease. J Neurochem. (2012) 123:159-71. doi: 10.1111/j.1471-4159.2012.07873.x

8. Ortiz-Sanchez P, Villalba-Orero M, Lopez-Olaneta MM, LarrasaAlonso J, Sanchez-Cabo F, Marti-Gomez C, et al. Loss of SRSF3 in cardiomyocytes leads to decapping of contractionrelated mrnas and severe systolic dysfunction. Circ Res. (2019) 125:170-83. doi: 10.1161/CIRCRESAHA.118.314515

9. Hogewind BF, Micheal S, Bakker B, Hoyng CB, den Hollander AI. Analysis of single nucleotide polymorphisms in the SFRS3 and FKBP4 genes in corticosteroid-induced ocular hypertension. Ophthalmic Genet. (2012) 33:221-4. doi: 10.3109/13816810.2012.716488

10. Fitzgerald KD, Semler BL. Re-localization of cellular protein SRp20 during poliovirus infection. bridging a viral ires to the host cell translation apparatus. PLoS Pathog. (2011) 7:e1002127. doi: 10.1371/journal.ppat.1002127

11. Jia R, Li C, McCoy JP, Deng CX, Zheng ZM. SRp20 is a proto-oncogene critical for cell proliferation and tumor induction and maintenance. Int J Biol Sci. (2010) 6:806-826. doi: 10.7150/ijbs.6.806

12. Majerciak V, Lu M, Li X, Zheng ZM. Attenuation of the suppressive activity of cellular splicing factor SRSF3 by kaposi sarcoma-associated herpesvirus ORF57 protein is required for RNA splicing. RNA. (2014) 20:1747-58. doi: 10.1261/rna.045500.114

13. Corbo C, Orru S, Salvatore F. SRp20. An overview of its role in human diseases. Biochem Biophys Res Commun. (2013) 436:15. doi: 10.1016/j.bbrc.2013.05.027

14. Long JC, Caceres JF. The SR protein family of splicing factors. Master regulators of gene expression. Biochem J. (2009) 417:15-27. doi: 10.1042/BJ20081501

15. Manley JL, Krainer AR. A rational nomenclature for serine/argininerich protein splicing factors (SR proteins). Genes Dev. (2010) 24:10734. doi: 10.1101/gad.1934910

16. Cowper AE, Caceres JF, Mayeda A, Screaton GR. Serinearginine (SR) protein-like factors that antagonize authentic SR proteins and regulate alternative splicing. J Biol Chem. (2001) 276:48908-14. doi: 10.1074/jbc.M103967200

17. Sapra AK, Anko ML, Grishina I, Lorenz M, Pabis M, Poser I, et al. SR protein family members display diverse activities in the formation of nascent and mature mRNPs in vivo. Mol Cell. (2009) 34:17990. doi: 10.1016/j.molcel.2009.02.031

18. Ratnadiwakara M, Archer SK, DeSong X, Wan X, nt CI, Ruiz De Los Mozos I, et al. SRSF3 promotes pluripotency through nanog mRNA export and coordination of the pluripotency gene expression program. Elife. (2018) 7:e37419. doi: 10.7554/eLife.37419

19. Do DV, Strauss B, Cukuroglu E, Macaulay I, Wee KB, Hu TX, et al. SRSF3 maintains transcriptome integrity in oocytes by regulation of alternative splicing and transposable elements. Cell Discov. (2018) 4:33. doi: 10.1038/s41421-018-0032-3

20. Sen S, Jumaa H, Webster NJ. Splicing factor SRSF3 is crucial for hepatocyte differentiation and metabolic function. Nat Commun. (2013) 4:1336. doi: $10.1038 /$ ncomms 2342

21. Ajiro M, Jia R, Yang Y, Zhu J, Zheng ZM. A genome landscape of SRSF3regulated splicing events and gene expression in human osteosarcoma U2OS cells. Nucleic Acids Res. (2016) 44:1854-1870. doi: 10.1093/nar/gkv 1500

22. Wang Z, Chatterjee D, Jeon HY, Akerman M, Vander Heiden MG, Cantley LC, et al. Exon-centric regulation of pyruvate kinase $\mathrm{M}$ alternative splicing via mutually exclusive exons. J Mol Cell Biol. (2012) 4:7987. doi: $10.1093 / \mathrm{jmcb} / \mathrm{mjr} 030$

23. Song $\mathrm{X}$, Wan $\mathrm{X}$, Huang $\mathrm{T}$, Zeng $\mathrm{C}$, Sastry $\mathrm{N}$, Wu B, et al. SRSF3Regulated RNA alternative splicing promotes glioblastoma tumorigenicity by affecting multiple cellular processes. Cancer Res. (2019) 79:5288301. doi: 10.1158/0008-5472.CAN-19-1504
24. Dewaele M, Tabaglio T, Willekens K, Bezzi M, Teo SX, Low DH, et al. Antisense oligonucleotide-mediated MDM4 exon 6 skipping impairs tumor growth. J Clin Invest. (2016) 126:68-84. doi: 10.1172/JCI82534

25. de la Mata M, Kornblihtt AR. RNA polymerase II C-terminal domain mediates regulation of alternative splicing by SRp20. Nat Struct Mol Biol. (2006) 13:973-80. doi: 10.1038/nsmb1155

26. He X, Ee PL, Coon JS, Beck WT. Alternative splicing of the multidrug resistance protein 1/ATP binding cassette transporter subfamily gene in ovarian cancer creates functional splice variants and is associated with increased expression of the splicing factors PTB and SRp20. Clin Cancer Res. (2004) 10:4652-60. doi: 10.1158/1078-0432.CCR-03-0439

27. Tang Y, Horikawa I, Ajiro M, Robles AI, Fujita K, Mondal AM, et al. Downregulation of splicing factor SRSF3 induces p53beta, an alternatively spliced isoform of p53 that promotes cellular senescence. Oncogene. (2013) 32:2792-8. doi: 10.1038/onc.2012.288

28. Kurokawa K, Akaike Y, Masuda K, Kuwano Y, Nishida K, Yamagishi N, et al. Downregulation of serine/arginine-rich splicing factor 3 induces G1 cell cycle arrest and apoptosis in colon cancer cells. Oncogene. (2014) 33:140717. doi: $10.1038 /$ onc. 2013.86

29. Brady LK, Wang H, Radens CM, Bi Y, Radovich M, Maity A, et al. Transcriptome analysis of hypoxic cancer cells uncovers intron retention in EIF2B5 as a mechanism to inhibit translation. PLoS Biol. (2017) 15:e2002623. doi: 10.1371/journal.pbio.2002623

30. Chen H, Gao F, He M, Ding XF, Wong AM, Sze SC, et al. Long-Read RNA sequencing identifies alternative splice variants in hepatocellular carcinoma and tumor-specific isoforms. Hepatology. (2019) 70:101125. doi: 10.1002/hep. 30500

31. Munoz U, Puche JE, Hannivoort R, Lang UE, Cohen-Naftaly M, Friedman SL. Hepatocyte growth factor enhances alternative splicing of the kruppellike factor 6 (KLF6) tumor suppressor to promote growth through SRSF1. Mol Cancer Res. (2012) 10:1216-27. doi: 10.1158/1541-7786.MCR-12-0213

32. Yang S, Jia R, Bian Z. SRSF5 functions as a novel oncogenic splicing factor and is upregulated by oncogene SRSF3 in oral squamous cell carcinoma. Biochim Biophys Acta Mol Cell Res. (2018) 1865:116172. doi: 10.1016/j.bbamcr.2018.05.017

33. Kuranaga Y, Sugito N, Shinohara H, Tsujino T, Taniguchi K, Komura K, et al. SRSF3, a splicer of the pkm gene, regulates cell growth and maintenance of cancer-specific energy metabolism in colon cancer cells. Int J Mol Sci. (2018) 19:3012. doi: $10.3390 /$ ijms 19103012

34. Hargous Y, Hautbergue GM, Tintaru AM, Skrisovska L, Golovanov AP, Stevenin J, et al. Molecular basis of RNA recognition and TAP binding by the SR proteins SRp20 and 9G8. EMBO J. (2006) 25:512637. doi: $10.1038 /$ sj.emboj. 7601385

35. Muller-McNicoll M, Botti V, de Jesus Domingues AM, Brandl H, Schwich OD, Steiner MC, et al. SR proteins are NXF1 adaptors that link alternative RNA processing to mRNA export. Genes Dev. (2016) 30:55366. doi: 10.1101/gad.276477.115

36. Park SK, Jeong S. SRSF3 represses the expression of PDCD4 protein by coordinated regulation of alternative splicing, export and translation. Biochem Biophys Res Commun. (2016) 470:431-8. doi: 10.1016/j.bbrc.2016.01.019

37. Huang Y, Steitz JA. Splicing factors SRp20 and 9G8 promote the nucleocytoplasmic export of mRNA. Mol Cell. (2001) 7:899-905. doi: 10.1016/S1097-2765(01)00233-7

38. Bedard KM, Daijogo S, Semler BL. A nucleo-cytoplasmic SR protein functions in viral IRES-mediated translation initiation. EMBO J. (2007) 26:459-67. doi: 10.1038/sj.emboj.7601494

39. Kim J, Park RY, Chen JK, Kim J, Jeong S, Ohn T. Splicing factor SRSF3 represses the translation of programmed cell death 4 mRNA by associating with the 5'-UTR region. Cell Death Differ. (2014) 21:48190. doi: $10.1038 /$ cdd.2013.171

40. Boutej H, Rahimian R, Thammisetty SS, Beland LC, Lalancette-Hebert M, Kriz J. Diverging mRNA and protein networks in activated microglia reveal srsf3 suppresses translation of highly upregulated innate immune transcripts. Cell Rep. (2017) 21:3220-33. doi: 10.1016/j.celrep.2017.11.058

41. Maniatis T, Reed R. An extensive network of coupling among gene expression machines. Nature. (2002) 416:499-506. doi: 10.1038/416499a 
42. Maciolek NL, McNally MT. Serine/arginine-rich proteins contribute to negative regulator of splicing element-stimulated polyadenylation in rous sarcoma virus. J Virol. (2007) 81:11208-17. doi: 10.1128/JVI.00919-07

43. Lou H, Neugebauer KM, Gagel RF, Berget SM. Regulation of alternative polyadenylation by U1 snRNPs and SRp20. Mol Cell Biol. (1998) 18:497785. doi: 10.1128/MCB.18.9.4977

44. Jimenez M, Urtasun R, Elizalde M, Azkona M, Latasa MU, Uriarte I, et al. Splicing events in the control of genome integrity. Role of SLU7 and truncated SRSF3 proteins. Nucleic Acids Res. (2019) 47:345066. doi: 10.1093/nar/gkz014

45. Karemore G, Gudjonsson T, Rask MB, Neumann B, Heriche JK, Pepperkok $\mathrm{R}$, et al. Profiling DNA damage response following mitotic perturbations. Nat Commun. (2016) 7:13887. doi: 10.1038/ncomms13887

46. Buratowski S. Connections between mRNA 3' end processing and transcription termination. Curr Opin Cell Biol. (2005) 17:257-261. doi: 10.1016/j.ceb.2005.04.003

47. Whitelaw E, Proudfoot N. Alpha-thalassaemia caused by a poly(A) site mutation reveals that transcriptional termination is linked to 3' end processing in the human alpha 2 globin gene. EMBO J. (1986) 5:291522. doi: 10.1002/j.1460-2075.1986.tb04587.x

48. Dichtl B, Blank D, Sadowski M, Hubner W, Weiser S, Keller W. Yhh1p/Cft1p directly links poly(A) site recognition and RNA polymerase II transcription termination. EMBO J. (2002) 21:4125-35. doi: 10.1093/emboj/cdf390

49. Cui M, Allen MA, Larsen A, Macmorris M, Han M, Blumenthal T. Genes involved in pre-mRNA 3'-end formation and transcription termination revealed by a lin-15 operon Muv suppressor screen. Proc Natl Acad Sci USA. (2008) 105:16665-70. doi: 10.1073/pnas.0807104105

50. Kim K, Nguyen TD, Li S, Nguyen TA. SRSF3 recruits DROSHA to the basal junction of primary microRNAs. RNA. (2018) 24:8928. doi: $10.1261 /$ rna.065862.118

51. Fernandez N, Cordiner RA, Young RS, Hug N, Macias S, Caceres JF. Genetic variation and RNA structure regulate microRNA biogenesis. Nat Commun. (2017) 8:15114. doi: 10.1038/ncomms15114

52. Kim HR, Shin CH, Lee H, Choi KH, Nam DH, Ohn T, et al. MicroRNA1908-5p contributes to the oncogenic function of the splicing factor SRSF3. Oncotarget. (2017) 8:8342-8355. doi: 10.18632/oncotarget.14184

53. Wang C, Li L, Yin Z, Zhang Q, Zhao H, Tao R, et al. An indel polymorphism within pre-miR3131 confers risk for hepatocellular carcinoma. Carcinogenesis. (2017) 38:168-76. doi: 10.1093/carcin/bgw206

54. He X, Zhang P. Serine/arginine-rich splicing factor 3 (SRSF3) regulates homologous recombination-mediated DNA repair. Mol Cancer. (2015) 14:158. doi: 10.1186/s12943-015-0422-1

55. Jumaa H, Wei G, Nielsen PJ. Blastocyst formation is blocked in mouse embryos lacking the splicing factor SRp20. Curr Biol. (1999) 9:899902. doi: 10.1016/S0960-9822(99)80394-7

56. Guo J, Jia J, Jia R. PTBP1 and PTBP2 impaired autoregulation of SRSF3 in cancer cells. Sci Rep. (2015) 5:14548. doi: 10.1038/srep14548

57. Jumaa H, Nielsen PJ. The splicing factor SRp20 modifies splicing of its own mRNA and ASF/SF2 antagonizes this regulation. EMBO J. (1997) 16:5077-5085. doi: 10.1093/emboj/16.16.5077

58. Elizalde M, Urtasun R, Azkona M, Latasa MU, Goni S, Garcia-Irigoyen O, et al. Splicing regulator SLU7 is essential for maintaining liver homeostasis. $J$ Clin Invest. (2014) 124:2909-20. doi: 10.1172/JCI74382

59. Lin JC, Lee YC, Tan TH, Liang YC, Chuang HC, Fann YC, et al. RBM4SRSF3-MAP4K4 splicing cascade modulates the metastatic signature of colorectal cancer cell. Biochim Biophys Acta Mol Cell Res. (2018) 1865:25972. doi: 10.1016/j.bbamcr.2017.11.005

60. Reed R. Mechanisms of fidelity in pre-mRNA splicing. Curr Opin Cell Biol. (2000) 12:340-5. doi: 10.1016/S0955-0674(00)00097-1

61. Hung LH, Heiner M, Hui J, Schreiner S, Benes V, Bindereif A. Diverse roles of hnRNP L in mammalian mRNA processing. A combined microarray and RNAi analysis. RNA. (2008) 14:284-96. doi: 10.1261/rna.725208

62. Jia R, Zhang S, Liu M, Zhang Y, Liu Y, Fan M, et al. HnRNP L is important for the expression of oncogene SRSF3 and oncogenic potential of oral squamous cell carcinoma cells. Sci Rep. (2016) 6:35976. doi: 10.1038/srep35976

63. Pai SG, Carneiro BA, Mota JM, Costa R, Leite CA, Barroso-Sousa R, et al. Wnt/beta-catenin pathway. modulating anticancer immune response. $J$ Hematol Oncol. (2017) 10:101. doi: 10.1186/s13045-017-0471-6
64. Clevers H, Nusse R. Wnt/beta-catenin signaling and disease. Cell. (2012) 149:1192-1205. doi: 10.1016/j.cell.2012.05.012

65. Corbo C, Orru S, Gemei M, Noto RD, Mirabelli P, Imperlini E, et al. Protein cross-talk in CD133+ colon cancer cells indicates activation of the Wnt pathway and upregulation of SRp20 that is potentially involved in tumorigenicity. Proteomics. (2012) 12:2045-59. doi: 10.1002/pmic.201100370

66. Kavak E, Najafov A, Ozturk N, Seker T, Cavusoglu K, Aslan T, et al. Analysis of the Wnt/B-catenin/TCF4 pathway using SAGE, genome-wide microarray and promoter analysis. Identification of BRI3 and HSF2 as novel targets. Cell Signal. (2010) 22:1523-35. doi: 10.1016/j.cellsig.2010.05.021

67. Goncalves V, Matos P, Jordan P. Antagonistic SR proteins regulate alternative splicing of tumor-related Rac1b downstream of the PI3-kinase and Wnt pathways. Hum Mol Genet. (2009) 18:3696-707. doi: 10.1093/hmg/ddp317

68. Goncalves V, Matos P, Jordan P. The beta-catenin/TCF4 pathway modifies alternative splicing through modulation of SRp20 expression. RNA. (2008) 14:2538-49. doi: 10.1261/rna.1253408

69. Belkhiri A, Zhu S, El-Rifai W. DARPP-32. From neurotransmission to cancer. Oncotarget. (2016) 7:17631-40. doi: 10.18632/oncotarget.7268

70. Zhu S, Chen Z, Katsha A, Hong J, Belkhiri A, El-Rifai W. Regulation of CD44E by DARPP-32-dependent activation of SRp20 splicing factor in gastric tumorigenesis. Oncogene. (2016) 35:1847-56. doi: 10.1038/onc.2015.250

71. Scarlata S, Singla A, Garwain O. Phospholipase Cbeta interacts with cytosolic partners to regulate cell proliferation. Adv Biol Regul. (2018) 67:712. doi: 10.1016/j.jbior.2017.09.004

72. Bavelloni A, Faenza I, Cioffi G, Piazzi M, Parisi D, Matic I, et al. Proteomicbased analysis of nuclear signaling. Plcbetal affects the expression of the splicing factor srp20 in friend erythroleukemia cells. Proteomics. (2006) 6:5725-34. doi: 10.1002/pmic.200600318

73. Song X, Zhang N, Han P, Moon BS, Lai RK, Wang K, et al. Circular RNA profile in gliomas revealed by identification tool UROBORUS. Nucleic Acids Res. (2016) 44:e87. doi: 10.1093/nar/gkw075

74. Barbagallo D, Caponnetto A, Cirnigliaro M, Brex D, Barbagallo C, D'Angeli F, et al. CircSMARCA5 inhibits migration of glioblastoma multiforme cells by regulating a molecular axis involving splicing factors SRSF1/SRSF3/PTB. Int J Mol Sci. (2018) 19:480. doi: 10.3390/ijms19020480

75. Mole S, McFarlane M, Chuen-Im T, Milligan SG, Millan D, Graham SV. RNA splicing factors regulated by HPV16 during cervical tumour progression. $J$ Pathol. (2009) 219:383-91. doi: 10.1002/path.2608

76. Wang H, Zhang CZ, Lu SX, Zhang MF, Liu LL, Luo RZ, et al. A coiled-coil domain containing 50 splice variant is modulated by serine/arginine-rich splicing factor 3 and promotes hepatocellular carcinoma in mice by the ras signaling pathway. Hepatology. (2019) 69:179-95. doi: 10.1002/hep.30147

77. Bowler E, Porazinski S, Uzor S, Thibault P, Durand M, Lapointe E, et al. Hypoxia leads to significant changes in alternative splicing and elevated expression of CLK splice factor kinases in PC3 prostate cancer cells. BMC Cancer. (2018) 18:355. doi: 10.1186/s12885-018-4227-7

78. Elias AP, Dias S. Microenvironment changes (in $\mathrm{pH}$ ) affect VEGF alternative splicing. Cancer Microenviron. (2008) 1:1319. doi: 10.1007/s12307-008-0013-4

79. Peiqi L, Zhaozhong G, Yaotian Y, Jun J, Jihua G, Rong J. Expression of SRSF3 is Correlated with carcinogenesis and progression of oral squamous cell carcinoma. Int J Med Sci. (2016) 13:533-9. doi: 10.7150/ijms.14871

80. Lu GY, Huang SM, Liu ST, Liu PY, Chou WY, Lin WS. Caffeine induces tumor cytotoxicity via the regulation of alternative splicing in subsets of cancer-associated genes. Int J Biochem Cell Biol. (2014) 47:8392. doi: 10.1016/j.biocel.2013.12.004

81. Chang YL, Liu ST, Wang YW, Lin WS, Huang SM. Amiodarone promotes cancer cell death through elevated truncated SRSF3 and downregulation of miR-224. Oncotarget. (2018) 9:13390-406. doi: 10.18632/oncotarget.24385

82. Chang JG, Yang DM, Chang WH, Chow LP, Chan WL, Lin HH, et al. Small molecule amiloride modulates oncogenic RNA alternative splicing to devitalize human cancer cells. PLoS ONE. (2011) 6:e18643. doi: 10.1371/journal.pone.0018643

83. Lu GY, Liu ST, Huang SM, Chang YL, Lin WS. Multiple effects of digoxin on subsets of cancer-associated genes through the alternative splicing pathway. Biochimie. (2014) 106:131-9. doi: 10.1016/j.biochi.2014.08.013 
84. Chang YL, Hsu YJ, Chen Y, Wang YW, Huang SM. Theophylline exhibits anti-cancer activity via suppressing SRSF3 in cervical and breast cancer cell lines. Oncotarget. (2017) 8:101461-74. doi: 10.18632/oncotarget.21464

85. Su YA, Yang J, Tao L, Nguyen H, He P. undetectable and decreased expression of kiaa1949 (phostensin) encoded on chromosome 6p21.33 in human breast cancers revealed by transcriptome analysis. J Cancer. (2010) 1:38-50. doi: $10.7150 /$ jca. 1.38

86. Ke H, Zhao L, Zhang H, Feng X, Xu H, Hao J, et al. Loss of TDP43 inhibits progression of triple-negative breast cancer in coordination with SRSF3. Proc Natl Acad Sci USA. (2018) 115:E3426-35. doi: 10.1073/pnas.1714573115

87. Schmidt M, Bohm D, von Torne C, Steiner E, Puhl A, Pilch $\mathrm{H}$, et al. The humoral immune system has a key prognostic impact in node-negative breast cancer. Cancer Res. (2008) 68:5405-13. doi: 10.1158/0008-5472.CAN-07-5206

88. Sotiriou C, Wirapati P, Loi S, Harris A, Fox S, Smeds J, et al. Gene expression profiling in breast cancer. Understanding the molecular basis of histologic grade to improve prognosis. J Natl Cancer Inst. (2006) 98:26272. doi: $10.1093 /$ jnci/djj052

89. Iborra S, Hirschfeld M, Jaeger M, Zur Hausen A, Braicu I, Sehouli J, et al. Alterations in expression pattern of splicing factors in epithelial ovarian cancer and its clinical impact. Int J Gynecol Cancer. (2013) 23:9906. doi: 10.1097/IGC.0b013e31829783e3

90. Kooi IE, Mol BM, Massink MP, de Jong MC, de Graaf P, van der Valk $\mathrm{P}$, et al. A meta-analysis of retinoblastoma copy numbers refines the list of possible driver genes involved in tumor progression. PLoS ONE. (2016) 11:e0153323. doi: 10.1371/journal.pone.0153323

91. Villegas VM, Gold AS, Wildner A, Ehlies F, Murray TG. Genomic landscape of retinoblastoma. Clin Exp Ophthalmol. (2014) 42:2-3. doi: 10.1111/ceo.12277

92. Xu L, Shen J, Jia J, Jia R. Inclusion of hnRNP L alternative exon 7 is associated with good prognosis and inhibited by oncogene srsf3 in head and neck squamous cell carcinoma. Biomed Res Int. (2019) 2019:9612425. doi: 10.1155/2019/9612425

93. Torres S, Garcia-Palmero I, Marin-Vicente C, Bartolome RA, Calvino E, Fernandez-Acenero MJ, et al. Proteomic characterization of transcription and splicing factors associated with a metastatic phenotype in colorectal cancer. J Proteome Res. (2018) 17:25264. doi: 10.1021/acs.jproteome.7b00548

94. Kim YJ, Kim BR, Ryu JS, Lee GO, Kim HR, Choi KH, et al. HNRNPA1, a splicing regulator, is an effective target protein for cervical cancer detection. Comparison with conventional tumor markers. Int J Gynecol Cancer. (2017) 27:326-31. doi: 10.1097/IGC.0000000000000868

95. Wang H, Lekbaby B, Fares N, Augustin J, Attout T, Schnuriger A, et al. Alteration of splicing factors' expression during liver disease progression. Impact on hepatocellular carcinoma outcome. Hepatol Int. (2019) 13:45467. doi: 10.1007/s12072-019-09950-7

96. He X, Arslan AD, Pool MD, Ho TT, Darcy KM, Coon JS, et al. Knockdown of splicing factor SRp20 causes apoptosis in ovarian cancer cells and its expression is associated with malignancy of epithelial ovarian cancer. Oncogene. (2011) 30:356-65. doi: 10.1038/onc.2010.426

97. Park WC, Kim HR, Kang DB, Ryu JS, Choi KH, Lee GO, et al. Comparative expression patterns and diagnostic efficacies of SR splicing factors and HNRNPA1 in gastric and colorectal cancer. BMC Cancer. (2016) 16:358. doi: 10.1186/s12885-016-2387-x

98. Kumar D, Das M, Sauceda C, Ellies LG, Kuo K, Parwal P, et al. Degradation of splicing factor SRSF3 contributes to progressive liver disease. J Clin Invest. (2019) 130:4477-91. doi: 10.1172/JCI127374

99. Kim HR, Hwang SJ, Shin CH, Choi KH, Ohn T, Kim HH. SRSF3-regulated miR-132/212 controls cell migration and invasion by targeting YAP1. Exp Cell Res. (2017) 358:161-70. doi: 10.1016/j.yexcr.2017.06.009

100. Jia R, Ajiro M, Yu L, McCoy P, Jr., Zheng ZM. Oncogenic splicing factor SRSF3 regulates ILF3 alternative splicing to promote cancer cell proliferation and transformation. RNA. (2019) 25:630-44. doi: 10.1261/rna.068 619.118

101. Gautrey H, Jackson C, Dittrich AL, Browell D, Lennard T, Tyson-Capper A. SRSF3 and hnRNP H1 regulate a splicing hotspot of HER2 in breast cancer cells. RNA Biol. (2015) 12:1139-51. doi: 10.1080/15476286.2015.1076610
102. Zhou L, Guo J, Jia R. Oncogene SRSF3 suppresses autophagy via inhibiting BECN1 expression. Biochem Biophys Res Commun. (2019) 509:96672. doi: 10.1016/j.bbrc.2019.01.048

103. Liu J, Huang B, Xiao Y, Xiong HM, Li J, Feng DQ, et al. Aberrant expression of splicing factors in newly diagnosed acute myeloid leukemia. Onkologie. (2012) 35:335-40. doi: 10.1159/000338941

104. Xu X, Yang J, Zhou W, Wang L, Lu Q, Wang X, et al. Genetic variations within alternative splicing associated genes are associated with breast cancer susceptibility in Chinese women. Gene. (2019) 706:1405. doi: 10.1016/j.gene.2019.05.022

105. Sen S, Langiewicz M, Jumaa H, Webster NJ. Deletion of serine/arginine-rich splicing factor 3 in hepatocytes predisposes to hepatocellular carcinoma in mice. Hepatology. (2015) 61:171-83. doi: 10.1002/hep.27380

106. Piekielko-Witkowska A, Wiszomirska H, Wojcicka A, Poplawski P, Boguslawska J, Tanski Z, et al. Disturbed expression of splicing factors in renal cancer affects alternative splicing of apoptosis regulators, oncogenes, and tumor suppressors. PLoS ONE. (2010) 5:e13690. doi: 10.1371/journal.pone.0013690

107. Bohgaki M, Tsukiyama T, Nakajima A, Maruyama S, Watanabe M, Koike $\mathrm{T}$, et al. Involvement of Ymer in suppression of NF-kappaB activation by regulated interaction with lysine-63-linked polyubiquitin chain. Biochim Biophys Acta. (2008) 1783:826-37. doi: 10.1016/j.bbamcr.2007.09.006

108. Farfsing A, Engel F, Seiffert M, Hartmann E, Ott G, Rosenwald A, et al. Gene knockdown studies revealed CCDC50 as a candidate gene in mantle cell lymphoma and chronic lymphocytic leukemia. Leukemia. (2009) 23:201826. doi: 10.1038/leu.2009.144

109. Kaneko S, Chen X, Lu P, Yao X, Wright TG, Rajurkar M, et al. Smad inhibition by the Ste20 kinase Misshapen. Proc Natl Acad Sci USA. (2011) 108:11127-32. doi: 10.1073/pnas.1104128108

110. Slamon DJ, Godolphin W, Jones LA, Holt JA, Wong SG, Keith DE, et al. Studies of the HER-2/neu proto-oncogene in human breast and ovarian cancer. Science. (1989) 244:707-12. doi: 10.1126/science.2470152

111. Jackson C, Browell D, Gautrey H, Tyson-Capper A. clinical significance of her-2 splice variants in breast cancer progression and drug resistance. Int $J$ Cell Biol. (2013) 2013:973584. doi: 10.1155/2013/973584

112. Kwong KY, Hung MC. A novel splice variant of HER2 with increased transformation activity. Mol Carcinog. (1998) 23:62-8. doi: 10.1002/(sici)1098-2744(199810)23:2<62::aid-mc2>3.0.co;2-o

113. Alajati A, Sausgruber N, Aceto N, Duss S, Sarret S, Voshol H, et al. Mammary tumor formation and metastasis evoked by a HER2 splice variant. Cancer Res. (2013) 73:5320-7. doi: 10.1158/0008-5472.CAN-12-3186

114. Aigner A, Juhl H, Malerczyk C, Tkybusch A, Benz CC, Czubayko F. Expression of a truncated $100 \mathrm{kDa}$ HER2 splice variant acts as an endogenous inhibitor of tumour cell proliferation. Oncogene. (2001) 20:2101-11. doi: 10.1038/sj.onc. 1204305

115. Cole SP, Bhardwaj G, Gerlach JH, Mackie JE, Grant CE, Almquist KC, et al. Overexpression of a transporter gene in a multidrug-resistant human lung cancer cell line. Science. (1992) 258:1650-4. doi: 10.1126/science.1360704

116. Zaman GJ, Versantvoort CH, Smit JJ, Eijdems EW, de Haas M, Smith AJ, et al. Analysis of the expression of MRP, the gene for a new putative transmembrane drug transporter, in human multidrug resistant lung cancer cell lines. Cancer Res. (1993) 53:1747-50.

117. Nooter K, Brutel de la Riviere G, Look MP, van Wingerden KE, HenzenLogmans SC, Scheper RJ, et al. The prognostic significance of expression of the multidrug resistance-associated protein (MRP) in primary breast cancer. Br J Cancer. (1997) 76:486-93. doi: 10.1038/bjc.1997.414

118. Endo K, Maehara Y, Ichiyoshi Y, Kusumoto T, Sakaguchi Y, Ohno S, et al. Multidrug resistance-associated protein expression in clinical gastric carcinoma. Cancer. (1996) 77(Suppl.8):16817. doi: 10.1002/(SICI)1097-0215(19961104)68:3<372::AID-IJC16>3.0.CO;2A

119. Norris MD, Bordow SB, Marshall GM, Haber PS, Cohn SL, Haber M. Expression of the gene for multidrug-resistance-associated protein and outcome in patients with neuroblastoma. N Engl J Med. (1996) 334:2318. doi: 10.1056/NEJM199601253340405

120. Fukuyama R, Niculaita R, Ng KP, Obusez E, Sanchez J, Kalady M, et al. Mutated in colorectal cancer, a putative tumor suppressor for serrated 
colorectal cancer, selectively represses beta-catenin-dependent transcription. Oncogene. (2008) 27:6044-55. doi: 10.1038/onc.2008.204

121. Luo W, Semenza GL. Emerging roles of PKM2 in cell metabolism and cancer progression. Trends Endocrinol Metab. (2012) 23:560-6. doi: 10.1016/j.tem.2012.06.010

122. Cmarik JL, Min H, Hegamyer G, Zhan S, Kulesz-Martin M, Yoshinaga $\mathrm{H}$, et al. Differentially expressed protein Pdcd4 inhibits tumor promoterinduced neoplastic transformation. Proc Natl Acad Sci USA. (1999) 96:14037-42. doi: 10.1073/pnas.96.24.14037

123. Lankat-Buttgereit B, Goke R. The tumour suppressor Pdcd4. Recent advances in the elucidation of function and regulation. Biol Cell. (2009) 101:309-17. doi: 10.1042/BC20080191

124. Prives C. Signaling to p53. Breaking the MDM2-p53 circuit. Cell. (1998) 95:5-8. doi: 10.1016/S0092-8674(00)81774-2

125. Danovi D, Meulmeester E, Pasini D, Migliorini D, Capra M, Frenk R, et al. Amplification of Mdmx (or Mdm4) directly contributes to tumor formation by inhibiting p53 tumor suppressor activity. Mol Cell Biol. (2004) 24:5835-43. doi: 10.1128/MCB.24.13.5835-5843.2004

126. Wade M, Li YC, Wahl GM. MDM2, MDMX and p53 in oncogenesis and cancer therapy. Nat Rev Cancer. (2013) 13:83-96. doi: 10.1038/nrc3430

127. Rallapalli R, Strachan G, Cho B, Mercer WE, Hall DJ. A novel MDMX transcript expressed in a variety of transformed cell lines encodes a truncated protein with potent p53 repressive activity. J Biol Chem. (1999) 274:8299308. doi: 10.1074/jbc.274.12.8299

128. Bezzi M, Teo SX, Muller J, Mok WC, Sahu SK, Vardy LA, et al. Regulation of constitutive and alternative splicing by PRMT5 reveals a role for Mdm4 premRNA in sensing defects in the spliceosomal machinery. Genes Dev. (2013) 27:1903-16. doi: 10.1101/gad.219899.113

129. Bartkova J, Rezaei N, Liontos M, Karakaidos P, Kletsas D, Issaeva $\mathrm{N}$, et al. Oncogene-induced senescence is part of the tumorigenesis barrier imposed by DNA damage checkpoints. Nature. (2006) 444:6337. doi: $10.1038 /$ nature 05268

130. Campisi J, d'Adda di Fagagna F. Cellular senescence. When bad things happen to good cells. Nat Rev Mol Cell Biol. (2007) 8:72940. doi: $10.1038 / \mathrm{nrm} 2233$

131. Prieur A, Peeper DS. Cellular senescence in vivo. A barrier to tumorigenesis. Curr Opin Cell Biol. (2008) 20:150-5. doi: 10.1016/j.ceb.2008.01.007

132. Sotillo E, Barrett DM, Black KL, Bagashev A, Oldridge D, Wu G, et al. Convergence of acquired mutations and alternative splicing of CD19 enables resistance to CART-19 immunotherapy. Cancer Discov. (2015) 5:128295. doi: 10.1158/2159-8290.CD-15-1020

133. Galiana-Arnoux D, Lejeune F, Gesnel MC, Stevenin J, Breathnach R, Del Gatto-Konczak F. The CD44 alternative v9 exon contains a splicing enhancer responsive to the SR proteins 9G8, ASF/SF2, and SRp20. J Biol Chem. (2003) 278:32943-53. doi: 10.1074/jbc.M301090200

134. Ajiro M, Tang S, Doorbar J, Zheng ZM. Serine/arginine-rich splicing factor 3 and heterogeneous nuclear ribonucleoprotein al regulate alternative rna splicing and gene expression of human papillomavirus 18 through two functionally distinguishable cis elements. J Virol. (2016) 90:913852. doi: 10.1128/JVI.00965-16

135. Ku BM, Lee YK, Jeong JY, Ryu J, Choi J, Kim JS, et al. Caffeine inhibits cell proliferation and regulates PKA/GSK3beta pathways in U87MG human glioma cells. Mol Cells. (2011) 31:275-9. doi: 10.1007/s10059-011-0027-5

136. Sun F, Han DF, Cao BQ, Wang B, Dong N, Jiang DH. Caffeineinduced nuclear translocation of FoxO1 triggers Bim-mediated apoptosis in human glioblastoma cells. Tumour Biol. (2016) 37:3417-23. doi: 10.1007/s13277-015-4180-x

137. Lu YP, Lou YR, Xie JG, Peng QY, Zhou S, Lin Y, et al. Caffeine and caffeine sodium benzoate have a sunscreen effect, enhance UVBinduced apoptosis, and inhibit UVB-induced skin carcinogenesis in SKH-1 mice. Carcinogenesis. (2007) 28:199-206. doi: 10.1093/carcin/bg 1112

138. Walsh CM, Suchanek AL, Cyphert TJ, Kohan AB, Szeszel-Fedorowicz $\mathrm{W}$, Salati LM. Serine arginine splicing factor 3 is involved in enhanced splicing of glucose-6-phosphate dehydrogenase RNA in response to nutrients and hormones in liver. J Biol Chem. (2013) 288:281628. doi: $10.1074 /$ jbc.M112.410803
139. Biamonti G, Bonomi S, Gallo S, Ghigna C. Making alternative splicing decisions during epithelial-to-mesenchymal transition (EMT). Cell Mol Life Sci. (2012) 69:2515-26. doi: 10.1007/s00018-012-0931-7

140. Monteiro JP, Alves MG, Oliveira PF, Silva BM. Structurebioactivity relationships of methylxanthines. Trying to make sense of all the promises and the drawbacks. Molecules. (2016) 21:974. doi: 10.3390/molecules 21080974

141. Shim JS, Liu JO. Recent advances in drug repositioning for the discovery of new anticancer drugs. Int J Biol Sci. (2014) 10:654-63. doi: 10.7150/ijbs.9224

142. Singh BN. Amiodarone as paradigm for developing new drugs for atrial fibrillation. J Cardiovasc Pharmacol. (2008) 52:300-5. doi: 10.1097/FJC.0b013e31818914b6

143. Kathofer S, Thomas D, Karle CA. The novel antiarrhythmic drug dronedarone. Comparison with amiodarone. Cardiovasc Drug Rev. (2005) 23:217-30. doi: 10.1111/j.1527-3466.2005.tb00167.x

144. Theodossiou TA, Galanou MC, Paleos CM. Novel amiodarone-doxorubicin cocktail liposomes enhance doxorubicin retention and cytotoxicity in DU145 human prostate carcinoma cells. J Med Chem. (2008) 51:606774. doi: 10.1021/jm800493j

145. Favoulet P, Cercueil JP, Faure P, Osmak L, Isambert N, Beltramo $\mathrm{JL}$, et al. Increased cytotoxicity and stability of lipiodol-pirarubicin emulsion compared to classical doxorubicin-Lipiodol. Potential advantage for chemoembolization of unresectable hepatocellular carcinoma. Anticancer Drugs. (2001) 12:801-6. doi: 10.1097/00001813-200111000-00003

146. Maresova L, Muend S, Zhang YQ, Sychrova H, Rao R. Membrane hyperpolarization drives cation influx and fungicidal activity of amiodarone. J Biol Chem. (2009) 284:2795-802. doi: 10.1074/jbc.M806693200

147. Stahl E, Ellis J. Novel allosteric effects of amiodarone at the muscarinic M5 receptor. J Pharmacol Exp Ther. (2010) 334:214-22. doi: 10.1124/jpet.109.165316

148. Swift PA, MacGregor GA. The epithelial sodium channel in hypertension. Genetic heterogeneity and implications for treatment with amiloride. Am J Pharmacogen. (2004) 4:1618. doi: 10.2165/00129785-200404030-00003

149. Kedzierska H, Piekielko-Witkowska A. Splicing factors of SR and hnRNP families as regulators of apoptosis in cancer. Cancer Lett. (2017) 396:5365. doi: 10.1016/j.canlet.2017.03.013

150. Jordan $\mathrm{P}$, Mannervik M, Tora $\mathrm{L}$, Carmo-Fonseca $\mathrm{M}$. In vivo evidence that TATA-binding protein/SL1 colocalizes with UBF and RNA polymerase I when rRNA synthesis is either active or inactive. J Cell Biol. (1996) 133:22534. doi: $10.1083 /$ jcb.133.2.225

151. Schnelzer A, Prechtel D, Knaus U, Dehne K, Gerhard M, Graeff H, et al. Rac1 in human breast cancer. Overexpression, mutation analysis, and characterization of a new isoform, Raclb. Oncogene. (2000) 19:301320. doi: 10.1038/sj.onc.1203621

152. Loh TJ, Choi N, Moon H, Jang HN, Liu Y, Zhou J, et al. Suppression of 5' splice-sites through multiple exonic motifs by hnRNP L. Biochim Biophys Acta Gene Regul Mech. (2017) 1860:363-73. doi: 10.1016/j.bbagrm.2017.01.010

153. Roundtree IA, He C. Nuclear $\mathrm{m}(6) \mathrm{A}$ reader YTHDC1 regulates mRNA splicing. Trends Genet. (2016) 32:320-1. doi: 10.1016/j.tig.2016.03.006

154. Roundtree IA, Luo GZ, Zhang Z, Wang X, Zhou T, Cui Y, et al. YTHDC1 mediates nuclear export of N(6)-methyladenosine methylated mRNAs. Elife. (2017) 6:e31311. doi: 10.7554/eLife.31311

155. Prudhomme M. Recent developments of rebeccamycin analogues as topoisomerase I inhibitors and antitumor agents. Curr Med Chem. (2000) 7:1189-212. doi: 10.2174/0929867003374138

156. Yoshida T, Kim JH, Carver K, Su Y, Weremowicz S, Mulvey L, et al. CLK2 is an oncogenic kinase and splicing regulator in breast cancer. Cancer Res. (2015) 75:1516-26. doi: 10.1158/0008-5472.CAN-14-2443

157. Siqueira RP, Barbosa Ede A, Poleto MD, Righetto GL, Seraphim TV, Salgado RL, et al. Potential antileukemia effect and structural analyses of SRPK Inhibition by N-(2-(Piperidin-1-yl)-5(Trifluoromethyl)Phenyl)Isonicotinamide (SRPIN340). PLoS ONE. (2015) 10:e0134882. doi: 10.1371/journal.pone.0134882

158. Rossi F, Labourier E, Forne T, Divita G, Derancourt J, Riou JF, et al. Specific phosphorylation of SR proteins by mammalian DNA topoisomerase I. Nature. (1996) 381:80-82. doi: 10.1038/381080a0 
159. Gui JF, Lane WS, Fu XD. A serine kinase regulates intracellular localization of splicing factors in the cell cycle. Nature. (1994) 369:67882. doi: $10.1038 / 369678 \mathrm{a} 0$

160. Colwill K, Pawson T, Andrews B, Prasad J, Manley JL, Bell JC, et al. The Clk/Sty protein kinase phosphorylates SR splicing factors and regulates their intranuclear distribution. $E M B O \quad J . \quad$ (1996) 15:265-75. doi: 10.1002/j.1460-2075.1996.tb0 0357.x

161. da Silva MR, Moreira GA, Goncalves da Silva RA, de Almeida Alves Barbosa E, Pais Siqueira R, Teixera RR, et al. Splicing regulators and their roles in cancer biology and therapy. Biomed Res Int. (2015) 2015:150514. doi: 10.1155/2015/150514

162. Soret J, Bakkour N, Maire S, Durand S, Zekri L, Gabut M, et al. Selective modification of alternative splicing by indole derivatives that target serinearginine-rich protein splicing factors. Proc Natl Acad Sci USA. (2005) 102:8764-8769. doi: 10.1073/pnas.0409829102
163. Ghigna C, De Toledo M, Bonomi S, Valacca C, Gallo S, Apicella M, et al. Pro-metastatic splicing of Ron proto-oncogene mRNA can be reversed. Therapeutic potential of bifunctional oligonucleotides and indole derivatives. RNA Biol. (2010) 7:495-503. doi: 10.4161/rna.7.4.12744

Conflict of Interest: The authors declare that the research was conducted in the absence of any commercial or financial relationships that could be construed as a potential conflict of interest.

Copyright (C) 2020 Zhou, Gong, Lin, Wang, Li, Wang, Ding and Li. This is an openaccess article distributed under the terms of the Creative Commons Attribution License (CC BY). The use, distribution or reproduction in other forums is permitted, provided the original author(s) and the copyright owner(s) are credited and that the original publication in this journal is cited, in accordance with accepted academic practice. No use, distribution or reproduction is permitted which does not comply with these terms. 